\title{
Factores, patrones y tendencias del crecimiento vertical en el área urbana de Medellín
}

Fabio de Jesús Vélez Macías*

Resumen. Se presentan los resultados de una investigación sobre las edificaciones mayores de cuatro pisos en la ciudad de Medellín. Se ha caracterizado el fenómeno en forma cuantitativa tomando como unidad espacial al barrio. Con base en información del municipio, se han determinado otras variables que permiten analizar la dinámica del crecimiento en términos temporales y relacionarla con aspectos socio-económicos. Se ha planteado una hipótesis estadística que ha sido probada parcialmente. Los factores tenidos en cuenta han sido el costo del suelo, reglamentación sobre índice de construcción, estrato socioeconómico del barrio, el área y uso previo del lote. El patrón se determinó geométricamente y las tendencias se analizaron por barrio. Palabras clave: crecimiento vertical, redensificación.

* Ingeniero Sanitario, MSc. en Geografía, docente de la Universidad de Antioquia.

E-mail: fabiovel@udea.edu.co 


\section{Introducción}

El fenómeno postmodernista del crecimiento vertical viene siendo observado desde principios del siglo pasado, cuando en las principales metrópolis de Estados Unidos se dio la constante y vertiginosa aparición de edificios y rascacielos, y la construcción de verdaderas ciudades subterráneas. Sin embargo esta situación, que ha llamado la atención de los geógrafos e investigadores de otras áreas del conocimiento, no ha producido muchas publicaciones al respecto. En nuestro medio, los estudios acerca del crecimiento de las ciudades han sido abordados principalmente desde el punto de vista bidimensional, es decir, de la expansión de las urbes hacia las zonas periurbanas.

Nuestras ciudades colombianas no han sido planeadas para el largo plazo sino que más bien, han ido respondiendo y adaptándose a la dinámica que le imprimen sus habitantes y las leyes del libre mercado. Adicionalmente, más que imponer códigos y hacer respetar estatutos, las administraciones locales, en general, han optado por el laissez faire y esto ha conducido a procesos caóticos del crecimiento. Ejemplos del fenómeno se dan en los Centros de las principales ciudades capitales del país (CBD), en donde se encuentran altos edificios junto a calles estrechas, que se convierten en escenarios de la disputa por el espacio entre vehículos y peatones En donde las condiciones ambientales se ven degradadas por el aumento en los niveles de ruido, gases y temperatura.
Cuando se analiza el crecimiento vertical de las ciudades, surgen una gran cantidad de preguntas que no han sido resueltas del todo en lo general, ni estudiadas en lo particular. Tampoco se han hecho acerca-mientos metodológicos que permitan su utilización en sucesivos estudios. Esto hace que cualquier aproximación al problema tenga cierto carácter de estudio explora-torio. La dinámica y evolución histórica de la redensificación en una ciudad, puede deberse a factores económicos, políticos, socio-culturales o físicos. Su análisis podría conducir a la identificación de patrones o tendencias, con los cuales se posibilite la construcción de un modelo que ayude al ejercicio prospectivo y a la planificación del desarrollo espacial urbano, y a detectar sus impactos de diferente tipo en el entorno urbano.

Este estudio, es un acercamiento al fenómeno del desarrollo de la construcción de edificios en la ciudad de Medellín. Se relaciona con los trabajos realizados por algunos economistas que han tratado los aspectos de la renta del suelo urbano, la plusvalía que surge al construir edificaciones en altura. También se entrelaza con las aproximaciones teóricas de algunas áreas de la Geografía (urbana, económica, política, social) que han estudiado el fenómeno tridimensional de las ciudades desde la posguerra y han llegado incluso a proponer algunos modelos e indicadores para su caracterización, cada una desde su perspectiva temática. Recoge también numerosos estudios locales en donde se encuentran censos de edificaciones, zonificaciones, análisis de fenómenos de crecimiento local, planes de desarrollo económico y territorial, que son de interés para la investigación.

62 Fabio de Jesús Vélez Macías 


\section{Referente espacial}

La unidad espacial mínima de análisis es el barrio. El marco espacial comprende el área urbana del municipio de Medellín cuya ubicación y conformación por barrios se ilustra en las figuras 1 y 2 .
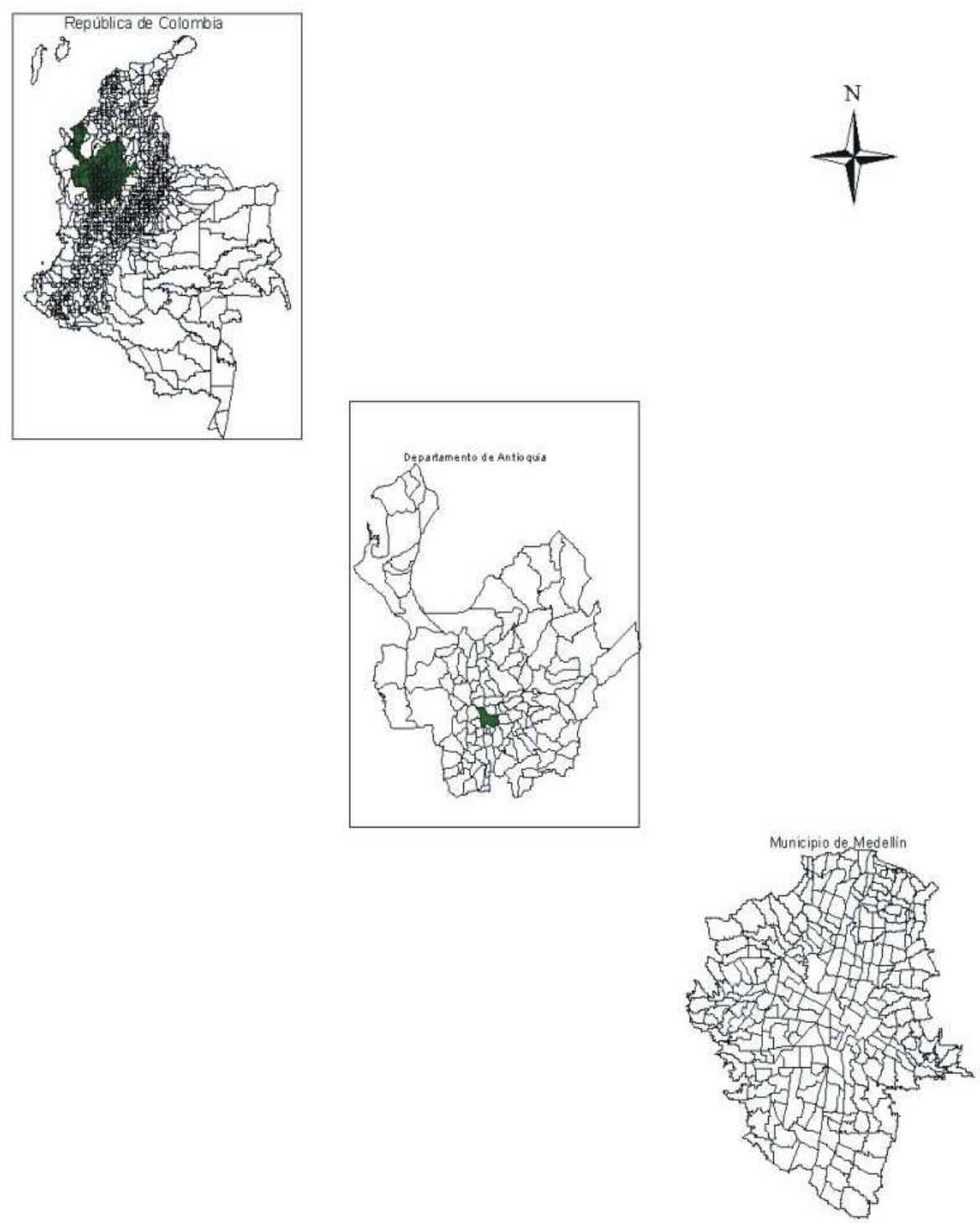

Figura 1

Localización geográfica municipio de Medellín

Perspectiva Geográfica 63 
Fuente: Planeación Metropolitana.

Figura 2

División administrativa por barrios área urbana municipio de Medellín

64 Fabio de Jesús Vélez Macías 


\section{Referente histórico}

Las construcciones de varios pisos han sido conocidas desde tiempos antiguos. Las razones para su materialización se debieron original y principalmente al culto religioso, y en pocos casos a la necesidad de suplir viviendas ante la saturación del espacio disponible. Para la tecnología disponible en la época, estas edificaciones debían realizarse en forma de conos truncados con gruesos muros en las bases que les servían de sostén. Sin embargo, su uso habitacional tuvo varios inconvenientes como el peligro de derrumbamiento e incendio, la incomodidad de ascender por escaleras, la falta de adecuación de algunos servicios básicos como dotación de agua y recolección de aguas servidas.

En la edad media, bajos edificios de tres y cuatro pisos fueron más comunes aunque las incomodidades siguieron persistiendo, agravándose con el hecho de que las calles eran demasiado estrechas. Ésto, junto con algunas costumbres sanitarias poco apropiadas como la disposición de excretas lanzadas desde los balcones a las mismas calles, fueron causantes de varias plagas y mortandad por epidemias en Europa.

Pero la era de los edificios y rascacielos comenzó en firme a finales del siglo XIX. Varios descubrimientos y desarrollos tecnológicos proporcionaron la vía para que se elevaran desde entonces, millones de edificios en el mundo con múltiples propósitos de uso. Vale la pena anotar, que el crecimiento vertical se da no sólo en forma aérea sino también en forma subterránea. Existen ya ejemplos importantes de este tipo de construcciones que constituyen verdaderas ciudadelas paralelas a las de la superficie y contribuyen a este tipo de crecimiento.

El concepto de rascacielos surge en el siglo XIX en Chicago, en donde, en palabras de Knox $(1994,152)$, «the technical preconditions for its development had coincided with the need to rebuild the center of the city after the fire of 1871». Estas precondiciones técnicas tienen que ver con el desarrollo de los elevadores, la construcción con estructura de acero, la energía eléctrica y más tarde el teléfono.

\section{El crecimiento vertical y urbano de Medellín}

A principios del siglo XX, la parte central de Medellín contaba con amplias casas de una planta, con patio y techo de teja. Las quebradas y el río Medellín se constituían en barreras para la urbanización por las inundaciones y el paludismo.

En 1932 se conformaron diferentes barrios al norte y al sur: los Ángeles, Prado, Aranjuez, Colón y el Poblado, La América, Belén, Robledo, Buenos Aires. Se vence la barrera del Río Medellín y comienza el poblamiento de la ciudad y el auge industrial. Se reconocía una carencia de técnica en las construcciones y en los materiales disponibles. Subyacía la tradición en cuanto a la conservación de aleros y altura en las construcciones. 
En 1948 se presenta el crecimiento hacia el occidente en los barrios Bolivariana, Laureles, La América y Belén, que se convertirán más adelante en foco de atención para los constructores de edificios. En 1950 es entregado por Wiener y Sert el Plan Piloto, primer plan de ordenamiento territorial, en el cual el río Medellín es considerado como el eje geográfico y vial. Este plan termina de ejecutarse en 1968 y para la época ya se observan los primeros edificios de la ciudad, la mayoría de ellos de uso administrativo y con la característica de estar muy dispersos. Estos eran, el Palacio Nacional, el Departamental, el Municipal, el de las EEPPM, del Idea, la Beneficencia de Antioquia, la Administración de Hacienda, la Caja Agraria, Telecom, el ICSS, el SENA, y el Comando Departamental. Los estudios de la época concluían que salvo estos edificios y algunos hoteles, no se apreciaba una tendencia al crecimiento vertical.

Luego se construyeron edificios bajos y ante el fenómeno de migración ruralurbana, masiva entre los años 50 y 60 , se presentó la demolición de casas para dar paso a edificios y urbanizaciones. La construcción en altura no tenía reglamentación por lo que no se presentó una unidad estética, ni se aplicaron conceptos arquitectónicos, desconociéndose el espacio externo. "La construcción acelerada de edificios ha tenido lugar especialmente en los barrios Poblado, Laureles y América" (Municipio de Medellín, 1991).
El crecimiento urbano comenzó a presentarse desde la década del 60. Las zonas son bien definidas y corresponden al centro de la ciudad y a algunos barrios. Según datos de 1964, en el centro principal 36 de 90 manzanas alcanzaban valores de hasta 10 veces su costo oficial, $83.8 \%$ de los lotes tenían un área menor de $600 \mathrm{~m}^{2}$, y el $89.5 \%$ ocupa lotes con frentes menores a $20 \mathrm{~m}$. El 38.41\% tenía áreas cercanas a $205 \mathrm{~m}^{2}$ y el $37.8 \%$ ocupaba frentes entre 6 y $10 \mathrm{~m}$. Los altos precios ocasionaban que los lotes fueran fragmentados y redensificados. Un estudio realizado por la firma SOLINGRAL, determinó que las zonas menos apropiadas para construcción de edificios eran, la avenida oriental entre calles 33 y San Juan, que más adelante, con otros sectores con limitaciones geotécnicas para la construcción de edificios como el barrio el Poblado, fueron redensificadas en la medida en que mejoraron las técnicas constructivas. Entre 1950 y 1970 , se presentan las primeras reglamentaciones pero aún no se contemplaban los aspectos volumétricos para la edificación en altura ni se tenían en cuenta conceptos del urbanismo en la toma de decisiones.

En el año 1969, se percibía en el centro de Medellín una tendencia a concentrarse y no a expandirse. Los nuevos materiales y equipos comienzan a dar paso a los primeros rascacielos ante el aumento del costo del suelo (se especula con valores de hasta 10 veces el costo real). Se percibe un mayor uso comercial mientras que los usos institucional e industrial tienden a ser desplazados del centro. El 
uso para vivienda se mantiene estacionario, lo que se compensa con la construcción en altura, presentándose un proceso de renovación urbana. Las cifras de la época señalan que un $13 \%$ del área está sin urbanizar. De esto, $0.68 \%$ son zonas verdes. El $2.9 \%$ corresponde a plazas y espacio público. El índice de construcción (área construida / área del lote) era de 1.98, muy cercano al que era considerado como nocivo en Alemania (2.00). Algunas consideraciones para el desarrollo de la época, fueron:

- Promover el desarrollo habitacional de alta densidad en el centro urbano (de 800 a $1000 \mathrm{Hab} / \mathrm{ha}$ ).

- Reducir, a escala peatonal, la distancia entre vivienda y sitio de trabajo.

- Redensificar el centro contemplando que la población residente en él no aumente.

En La carrera de los Rascacielos (Revista Ingeniería, Arquitectura, Construcción, 1971, 21), se destaca como las grandes empresas del país asumían la etapa de los rascacielos con fines comerciales: "un rascacielos representa el poder de una empresa, su gran alcance, es la identificación de una compañía en el espacio urbano. De alguna manera, el edificio "símbolo" es una forma de publicidad que representa siempre la imagen de una empresa en una comunidad". Y advertía que si se continuaba con la carrera de los rascacielos sin control, la anarquía llevaría a producir excesos de formalismo y el centro de la ciudad no sería un espacio coordinado estéticamente.
Estrada (1995), menciona la aparición de edificios en Medellín, según cuatro periodos:

- Entre 1900 y 1930: cuando la ciudad tiene un tamaño pequeño y sus edificaciones están concentradas alrededor del Parque de Berrío, y sobre las calles Bolivar, Boyacá, Colombia, Palacé y Carabobo. La altura de los edificios fluctuaba entre dos y cuatro pisos. El Edificio Henry, construido en 1928, es una excepción para la época, con siete pisos. Los usos primordiales son el comercial y de servicios, presentándose oficinas de profesionales, bancos y almacenes (en el primer piso). Con la llegada del ascensor en los años 20, se puede pensar en el aumento de la altura de las edificaciones, tal como sucedió con el edificio Olano.

- Entre 1930 y 1960: el centro se extiende y prolonga hacia el occidente. Los edificios se emplazan sobre la calle Colombia hasta el río, y sobre Junín hacia la avenida $1^{\circ}$ de mayo. En su mayoría son sedes bancarias que ya alcanzaban alturas entre siete y quince pisos.

- Entre 1960 y 1980: se expande el centro de la ciudad ante la gran concentración de actividades con las consecuentes congestiones peatonal y vehicular. Ya se comienza a notar la contaminación ambiental. Los edificios se emplazan en sitios que actúan como tensores para la ampliación del centro: avenidas La Playa, Colombia hacia La Oriental, Sucre hacia Ayacucho, y la construcción traspasa el río Medellín hacia el occidente (caso de los edificios Camacol y Suramericana). 
- De 1980 en adelante: aparece un nuevo polo de atracción sobre la avenida Oriental hacia el sur, que se extiende linealmente por la avenida El Poblado, en una configuración de edificios empresariales y financieros.

En 1969, los estudios del Municipio de Medellín (xxxi), identificaban en el Centro de la ciudad la especulación con el precio del suelo con el consiguiente fraccionamiento exagerado de lotes y una alta redensificación en ciertos sectores mientras que otros permanecían subutilizados. Entre los aspectos que promueve la redensificación en las ciudades y que estuvieron presentes en Medellín, se citan:

- Economías en tendido de redes y dotación de servicios públicos para servir a un mayor número de habitantes.

- Economía en la dotación de servicios sociales comunitarios para una población más concentrada.

- Economía en transporte urbano al presentar una oferta de actividades económicas en una área más concentrada sin que se presione el sistema de movilización.

- Promoción en la generación de empleo mediante la construcción masiva.

- Deterioro del centro de la ciudad que incentiva el desplazamiento de los moradores hacia otras zonas de mejores características urbanas.
A finales de los años 60 , cuando se inició la construcción de edifícios para vivienda en Medellín, ésta tuvo mayor aceptación en las clases sociales altas, principalmente por los conceptos de seguridad y comodidad. Además seleccionaban lugares cercanos a los Centros Comerciales sin importar la distancia que hubiere a los lugares de estudio y trabajo. Para los estratos socio - económicos medio y bajo, la poca aceptación se dio principalmente por los conceptos de independencia, tranquilidad y no tener que utilizar escaleras. Seleccionaban los lugares por su cercanía a la iglesia y a los lugares de estudio y trabajo (Municipio de Medellín, 1969).

En 1988, la Administración Metropolitana (Área Metropolitana, 1988) en el Estatuto de usos del suelo, urbanismo y construcción, reconoce la alta concentración poblacional a la que se ha llegado en ciertas zonas de la ciudad, alcanzando un valor promedio de $183 \mathrm{hab} /$ ha. Para los edificios de más de cuatro pisos, normaliza una distancia de once metros entre el paramento y el eje de la vía más próxima (54). El POT zona sur (42), destacan las altas densidades poblacionales que se presentan en algunos barrios como Castilla (430 hab/ha), en contraste con El Poblado que para la época contaba con $32 \mathrm{hab} / \mathrm{ha}$. De allí surge la política de promover la densificación de éste último.

En el artículo 77 del Estatuto Metropolitano de Planeación (Área Metropolitana, 1988), se especifica que

68 Fabio de Jesús Vélez Macías 
"no se contabilizarán como pisos hasta un máximo de cuatro niveles, los sótanos y semisótanos que se destinen en forma total a garaje o parqueadero privado, de visitantes, utilizados exclusivamente como instalaciones mecánicas, escaleras y tanques de agua y los destinados totalmente a áreas libres comunes para recreación. Tampoco un nivel de mezanine si está integrado al primer piso y su área no supera el $70 \%$ de este. Se incluyen los niveles que se construyan utilizando la inclinación del techo (áticos). Tanto los mezanines como los áticos se contabilizarán en el índice de construcción".

En 1991, el Departamento Administrativo de Planeación Metropolitana del Municipio de Medellín (DAPM), hacía la siguiente reflexión (45): Medellín pasó de ser una ciudad en cuyo centro, a principios de siglo, albergaba casas de un solo piso, con patio interior y techo de teja, a la ciudad moderna con edificios y urbanizaciones que se abrieron paso en los años 50 y 60 mediante las demoliciones de aquellas casas. De acuerdo con lo anterior, la relación casa calle ha sido paulatinamente sustituida por la relación edificio - avenida. Esta sustitución puede plantearse también como un desarrollo en detrimento del peatón y en beneficio del automóvil particular. En la actualidad, el habitante del apartamento realiza un recorrido cotidiano cuyo contacto con el espacio público es prácticamente nulo: apartamento - ascensor parqueadero privado-automóvil - avenida - nuevo parqueadero privado - ascensor oficina (52).
Según cifras para 1988 de Planeación Metropolitana (Actividad edificadora en el Área Metropolitana, 1988), en el estrato alto se otorgaron un total de 1.717 licencias provisionales para la construcción de casas unifamiliares. En Laureles durante el mismo año, el estrato medio alto obtuvo 754 licencias provisionales para construir edificios y sólo 6 para construir casas. Coincide esta situación con el Plan Vial para construir avenidas y puentes según la densidad del tráfico automotor, ante el aumento de vehículos particulares.

Como se aprecia, la capital del departamento de Antioquia no ha estado ajena a los fenómenos socio económicos y políticos que ha vivido el país y por el contrario, algunos han tenido como epicentro a la ciudad de Medellín. Algunas de las manifestaciones de la ocurrencia de dichos fenómenos se materializan en la aparición de edificios o por el contrario, en la parálisis de su construcción. Basta citar como ejemplos, el auge de la industrialización con su expresión de poder en las edificaciones en altura; la irrupción del narcotráfico y sus inversiones en el sector inmobiliario; la especulación consuetudinaria con el precio del suelo; las políticas de los gobiernos para la vivienda de interés social, sus medidas para facilitar el crédito hipotecario y el dinamismo que le inyectó al sector constructor; la actual recesión económica con sus consecuencias en todos los sectores productivos. 


\section{Referente conceptual}

\section{El edificio}

Por edificio se entiende una estructura vertical que supera los cinco pisos de altura y por lo tanto cuenta con varios desarrollos tecnológicos en su diseño y construcción. Cinco pisos parece ser un límite físico que está relacionado con la capacidad y sentido de la comodidad de un humano promedio para ascender por una escalera. Según los estándares, a mayores alturas es necesario el uso del ascensor para alcanzar estos niveles sin apremio.

En la modernidad los edificios tuvieron su "boom" a principios del siglo XX en los Estados Unidos en donde el desarrollo del concreto armado, los perfiles de acero, el invento del ascensor, la adaptación de sistemas de iluminación, ventilación, hidráulicos, de comunicaciones, permitió que fueran una alternativa para vivienda y concentración de personal de poderosas empresas.

Bourne (1971, 327) destaca dos tipos de construcción de edificios de apartamentos: por redesarrollo o reemplazo de edificaciones, generalmente en el centro y nuevas construcciones en tierras vacantes. En el primer caso, los constructores encuentran costos del suelo extremadamente altos, también de demolición y pérdida de ingresos por edificios existentes que no encaran desarrollos suburbanos. También se ve ejercida una mezcla de factores de localización en el desarrollo de ambientes urbanos, que produce un efecto en la potencialidad de un sitio para atraer nueva inversión. El ambiente y vecindario ejercen un profundo efecto en las nuevas áreas suburbanas pero no rebasan el efecto derivado de lo establecido por los patrones físicos y sociales. Estas nuevas áreas ofrecen una uniformidad social (más placentera) que las de las obvias ventajas de la centralidad (mezcla de usos y ambiente).

Los primeros 8 a 19 pisos de los edificios fueron construidos en Chicago entre 1879 y 1895, después del incendio de 1870. A partir de 1895, Manhattan superó a Chicago en la altura y numero de edificios (Sobresalen el Empire State Building con 102 pisos y 379 metros de altura; el World Trade Center de 109 pisos y 410 metros; y el Sears con 443 metros, en Chicago). Los rascacielos fueron estructuras típicas de las ciudades norteamericanas pero hoy están presentes en el mundo entero (Zárate, 1991, 58).

La figura 3 ilustra el Iron Building, uno de los primeros rascacielos construídos en Nueva York y el famoso Empire State, símbolo ya secular de la misma ciudad.

Los avances en las técnicas constructivas, los nuevos materiales, y la introducción de mejoras en los diseños (ascensores rápidos y seguros, protección de los edificios contra el peligro de incendio), no sólo hicieron posible la construcción de edificios muy altos, sino que estos resultaron mucho más rentables. El valioso espacio de las plantas bajas ya no tuvo que desperdiciarse para acomodar 
The Iron Building, New York

The Empire State, New York
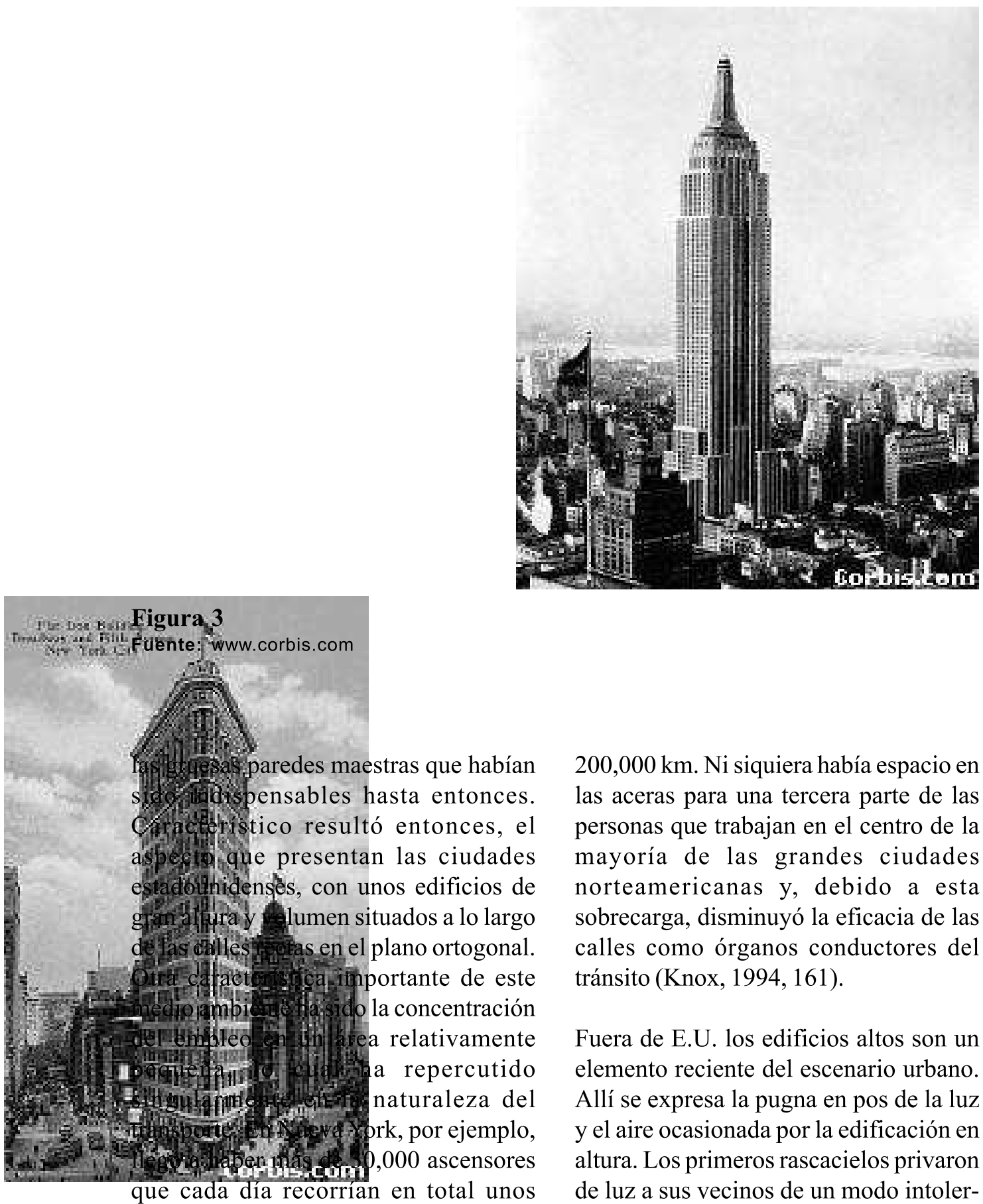

$200,000 \mathrm{~km}$. Ni siquiera había espacio en las aceras para una tercera parte de las personas que trabajan en el centro de la mayoría de las grandes ciudades norteamericanas $\mathrm{y}$, debido a esta sobrecarga, disminuyó la eficacia de las calles como órganos conductores del tránsito (Knox, 1994, 161).

Fuera de E.U. los edificios altos son un elemento reciente del escenario urbano. Allí se expresa la pugna en pos de la luz y el aire ocasionada por la edificación en altura. Los primeros rascacielos privaron de luz a sus vecinos de un modo intoler- 
able y a consecuencia de ello, se promulgaron en E.U. una serie de ordenanzas restrictivas que mejoraron la situación en la década de 1930. Se aseguró que los futuros edificios recibieran una cantidad suficiente de luz, y que al mismo tiempo no redujeran indebidamente la que han de recibir los edificios vecinos (162).

Según Zárate (1992, 38), el paisaje urbano o morfología de la ciudad es el producto de la acción combinada y dinámica de tres elementos: el plano, la construcción o edificación, y los usos del suelo. Este último es el de mayor variabilidad mientras que los dos primeros responden al costo de la inversión. La construcción urbana a su vez (52), está integrada por el entramado, la tipología de los edificios y el volumen de la edificación. Dentro de esta edificación existe una gran variedad desde el punto de vista funcional, de la forma y de la altura: bloques, torres y rascacielos (58):

Los bloques: edificios de forma rectangular y de varias plantas, unos denominados laminares o de doble crujía y otros, cerrado o de triple crujía.

Las torres: se caracterizan por su mayor altura, aparecen aisladas y agrupadas en pequeño número.

Los rascacielos: definidos en algunos países como construcciones de más de 28 pisos, constituyen hoy la edificación en altura más característica de las ciudades.

\section{La Economía en el crecimiento vertical}

Jaramillo (1994, 3), a partir de la "teoría general de la renta de la tierra" planteada por Carlos Marx, desarrolla una propuesta para el suelo urbano dada la importancia sin precedentes de la propiedad de la tierra urbana, al igual que el aumento del peso específico de las ciudades en las fases recientes del capitalismo. Destaca la importancia de la tierra en la ciudad porque "se relaciona no solamente con un proceso productivo, la construcción, sino con todos los procesos que utilizan el espacio construido como asiento, es decir, con las diversas actividades urbanas" (10). De las definiciones marxistas para las modalidades de las rentas, son interesantes las siguientes (18):

- Renta primaria diferencial tipo I (RPDTI): tiene que ver con la diversa intensidad de construcción. En el terreno urbano, la cualidad de un lote es la "constructibilidad", que se relacionan con una serie de características geomorfológicas de la tierra, que están desigualmente repartidas en los diferentes lotes (144). Su importancia tiende a disminuir en la medida en que se desarrollan la ingeniería y las técnicas constructivas. Una contratendencia a esta particularidad es, la utilización cada vez más frecuente de la construcción en altura que magnifica el efecto económico de ciertas heterogeneidades geomorfológicas de los terrenos (145 y 146). Otra fuente de esta renta en la ciudad es la localización, sobre

72 Fabio de Jesús Vélez Macías 
todo en el proceso de consumo del espacio construido y no tanto en su producción.

- Renta primaria diferencial tipo II (RPDTII): tiene un papel mucho más importante en la modulación de los precios del suelo urbano y se relaciona con la diferente intensidad de capital aplicado a la tierra. En el mercado urbano, este mecanismo cobra especial relevancia en la medida en que se materializa en la producción en altura, a través de la cual es posible multiplicar por un gran número de veces el espacio construido que se puede edificar en un lote de terreno, en comparación con lo que se podría denominar, una intensidad de construcción básica, de una sola planta.

En las ciudades capitalistas existe una fuerte presión por construir en altura en algunas de las áreas, lo que ha desembocado en la proliferación de enormes estructuras que son un rasgo distintivo y un símbolo de la urbanización capitalista. Esa enorme densidad de construcción en ciertos sitios coexiste en una misma ciudad, con densidades muy bajas en otros lugares, y muchas veces los proyectos son desarrollados, en ambos casos, por capital inmobiliario similar, cuando no se trata del mismo. Esta pauta de ocupación del suelo conlleva además, una paradoja: en la medida que se multiplica el número de niveles, el costo de producción unitario del espacio construido se eleva por los costos adicionales, aunque con cierta discontinuidad: la cimentación y la estructura deben ser más sofisticadas (resistente a sismos y a vientos); a partir de cierta altura se deben usar aparatos para la circulación vertical; se deben reservar espacios considerables del espacio construido para este y otros dispositivos (ductos, tanques). Además de que el tiempo de construcción se prolonga considerablemente (147-148).

Como el precio del espacio construido en cada lugar está relacionado con las rentas que los terrenos originales soportan, se puede deducir que la producción en altura depende de las rentas que existan con anterioridad al proceso de densificación. Se hace entonces necesario que el precio del suelo sea lo suficientemente elevado para que compense la utilización de técnicas en altura, que son más costosas pero que emplean menos terreno (el constructor sustituye tierra por capital). Esto tal vez explica porque la producción en mayor altura generalmente se localiza en los terrenos de precio más alto, como en el centro de la ciudad (contrario a lo que ocurre en la periferia).

Se constituye de esta forma que, tanto la RPDTII como las diferentes densidades de construcción en las distintas zonas de la ciudad, son fenómenos relacionados, $\mathrm{y}$ los agentes reguladores son: los costos de producción de las técnicas alternativas y su intensidad de construcción, y los precios del espacio construido en cada lugar específico. En cuanto a las reglamentaciones sobre ocupación del suelo urbano, a lo sumo las normas que limitan la altura y la densidad merecen la pena ser mencionadas, en una estructura que tiene su propia dinámica (155). 
Una renta que tiende a crecer con el aumento de la demanda por espacio construido es la RPDTII. Una vez que la magnitud de la renta local sobre un terreno sobrepasa cierto nivel, se hace viable la producción en altura, densificándose la ciudad. Esto implica que las rentas generales que emergen de la ciudad se canalizan en un menor número de terrenos (189).

E1 crecimiento en los costos de producción del espacio construido, no guarda una continuidad con respecto al número de niveles de la edificación, sino que existen a su vez ciertos saltos: el costo unitario de producir un metro cuadrado de espacio construido se dispara, cuando se sobrepasan los cinco o seis pisos. Vuelve a presentarse una discontinuidad más allá de los veinte pisos. Esto implica que el precio del espacio construido en cada zona, está dentro de determinados rangos y en la medida en que, en las distintas zonas de la ciudad se van alcanzando los umbrales del precio del espacio construido, estas aceleraciones en el incremento de la renta se van desplazando espacialmente (195).

La construcción de edificios se basa en los principios de la demanda y en teorías universales de renta e inversión. Cada proyecto es el resultado de la acción de varios agentes sociales y entidades mediadoras (decision makers $\mathrm{e}$ instituciones). En el otro platillo de la balanza está la probable alza de los precios del suelo producida por la restricción, sin más, de la expansión urbana, con lo que aumenta el costo de las viviendas y por ende, de la vida. Podría ser más conveniente limitar la expansión de la ciudad central y permitir, en cambio, el desarrollo de una serie de núcleos satélites. Estos núcleos se beneficiarían económicamente de la presencia de la ciudad central y por otra parte, disminuiría el número de movimientos pendulares diarios (Knox, 207).

Contrario a esta idea se muestra Hoch (en Perloff, 1973, 95), quien dice que "con frecuencia se afirma que los edificios altos son la causa de los elevados valores del suelo. Probablemente esta sea una versión poco elaborada del caso en que tanto la altura de los edificios como los elevados valores del suelo son causados por un precio relativamente elevado del espacio útil. Una mayor elaboración de este caso podría basarse en el papel de la imperfecta información y del riesgo, propios del mundo real. Si un empresario decide que el mercado pide en la actualidad un tipo de edificio más alto que el que existía anteriormente en un lugar determinado, corre un riesgo, y si tiene éxito, obtendrá unos beneficios que reflejarán su sagacidad o su suerte. Por lo tanto los efectos del riesgo pueden verse como un componente del factor empresarial, por lo menos en sentido ex -ante. Ex-post, constituirán parte del precio del suelo".

El riesgo puede utilizarse para explicar fenómenos tales como la existencia de edificios contiguos de distinta altura. Nentze (en Perloff, 1973, 95) enfoca el problema general y decide que "existe un elevado grado de incertidumbre ex - ante, 
de forma que la altura óptima puede variar a lo largo de amplias gamas, dependiendo de las estimaciones del promotor acerca de los valores de los parámetros claves".

Es importante destacar como en algunos casos, la presencia de ciertas estructuras de valor cultural, arquitectónico, , imponen algún tipo de restricción a la presión constructiva de grandes edificios. Es el caso de la gran mole de la catedral de San Pablo en Nueva York, que constituye una anomalía importante ya que no sólo afecta al área que ocupa realmente, sino que, por imperativos estéticos, también limita la altura de los edificios comerciales circundantes y les impone ciertas reglas arquitectónicas. De ahí que la forma del centro de casi todas las ciudades no sea sólo una cuestión de economía del suelo, aunque este factor tenga la mayor importancia. Pero no siempre se da esta situación. A veces las iglesias quedan sumergidas entre edificios. Quizá esto indique cierta relación con un "desafío simbólico" entre la autoridad temporal y la espiritual.

También vale la pena reseñar fenómenos que se presentaron en los países desarrollados y que luego fueron replicados en nuestro medio. Es el caso del auge de la construcción de viviendas en Gran Bretaña (1935), que se debió a varios factores. Uno de los más importantes fue el vigoroso desarrollo de las building societies, compañías de ahorro y crédito inmobiliario, que con la caída de las tasas de interés y la baja de precio de los materiales de construcción ayudaron a reducir los costos reales de la vivienda. Estos grandes constructores tendían a edificar extensos polígonos residenciales. Ello otorgaba a las grandes compañías otra ventaja, y era que se ahorraban la mano de obra en la construcción de los grandes conjuntos de vivienda, en comparación con los grupos más reducidos. También se beneficiaban con la compra de materiales en grandes cantidades y con la construcción normalizada.

\section{El uso del suelo en las zonas redensificadas}

En las ciudades existen variaciones en la intensidad del uso: por ejemplo, para la actividad comercial la máxima intensidad se registra en los puntos de precios del suelo más altos y de mayor densidad de tráfico. Las distintas actividades ocupan diferentes valores, así que se puede hablar de una zonificación de usos del suelo en horizontal y en vertical, según la renta del suelo. El comercio al por menor que requiere situarse en las zonas de mayor circulación, buscará los primeros pisos para atraer la atención del peatón, y así mismo pagará la renta más alta. Las oficinas buscarán los pisos superiores. Normalmente, los últimos pisos serán ocupados por apartamentos lujosos, sedes de compañías o restaurantes de cierta categoría, quienes buscan la tranquilidad y el paisaje (Zárate, 1991, 76). O como bien lo dice Hoch (Perloff, 1973, 96), "quizás el consumidor individual valore el acceso a la luz, al aire y a una vista sin obstrucciones. Algunos consumidores están dispuesto a pagar un precio elevado 
que refleje menos ruidos y polvo, menos polución de aire, una vista mejor, o el mayor prestigio que se supone, se asocia a una mayor altura".

Bravo (spi, 120), justifica el crecimiento vertical del centro de las ciudades según los siguientes factores: la política e intenciones de los planificadores, aumento de la renta del suelo, good will del centro, poco desarrollo de los centros satelitales, mayor intensidad de la actividad comercial, incremento en el flujo circulatorio. A su vez, la redensificación ocasiona el deterioro de la zona, alta demanda de servicios, aumento en los gravámenes de valorización (reavalúo catastral).

Carter (249) refieriéndose al modelo de Burgess (figura 4), hace los siguientes comentarios:

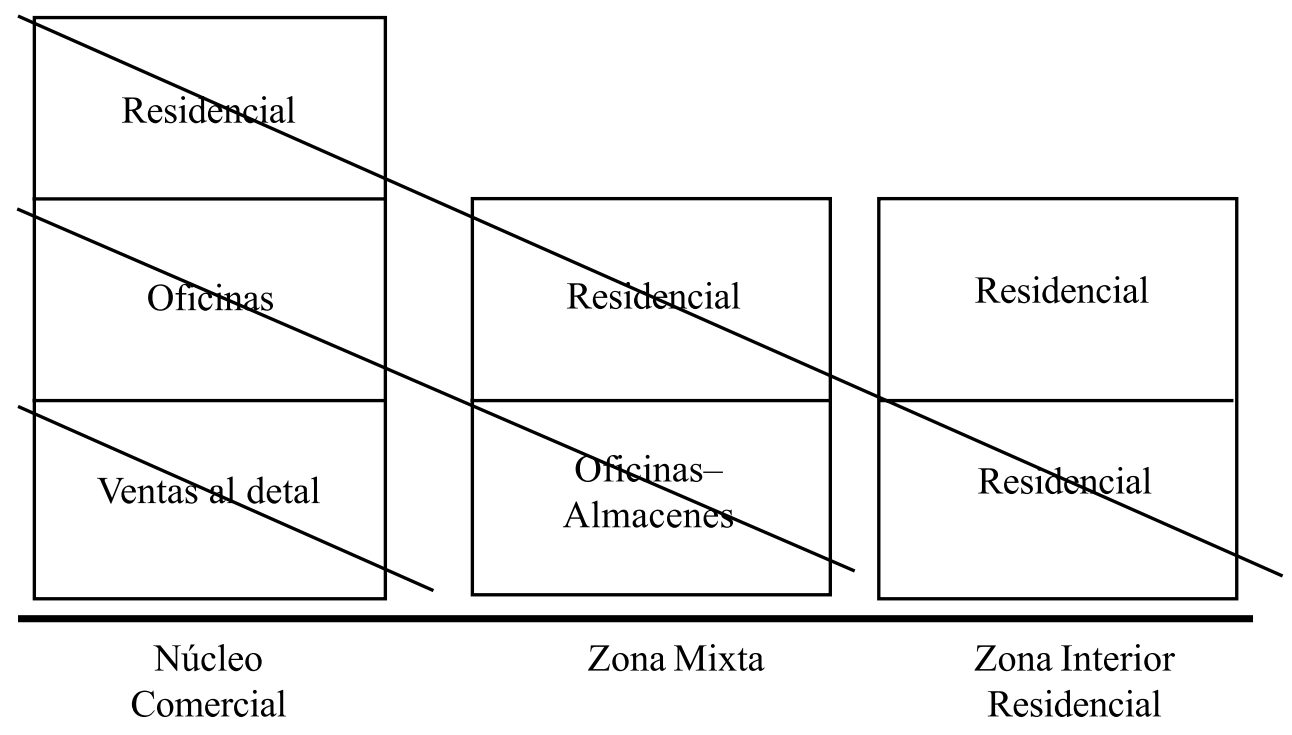

Figura 4. Modelo de Burgess

Fuente: Carter, 1980: 250.

El modelo de las zonas concéntricas parece dar a entender implícitamente que la ciudad es una figura bidimensional, habiéndose prestado en su formulación, muy poca atención a la altura de los edificios y a la variación de los usos del suelo en función de la altura. No obstante, resulta bastante sencillo, dentro de los límites de conjunto que ofrece el modelo mismo, introducir dicho rasgo o característica. La accesibilidad no solamente disminuye con el alejamiento desde el centro hacia el exterior, sino también con el aumento de la altura desde 
el suelo hacia arriba. Si se considera lo que podríamos denominar, cambios verticales en el uso del suelo, nos encontraremos que con frecuencia guardan un cierto paralelismo con los cambios horizontales.

Las tiendas, que requieren un acceso inmediato a partir de la calle para que el negocio prospere, han de pagar los elevados alquileres que se les pide a los locales de planta baja. Los despachos de abogados y las oficinas de los mayoristas estarán en pisos altos con actividades no características del CBD, como por ejemplo almacenes de mercancías y ciertos tipos de industria. Las variaciones verticales en los alquileres, íntimamente asociadas con estas diferentes utilizaciones, son análogas a las variaciones horizontales que se presentan a lo largo de un radio trazado a partir del área de los precios máximos del suelo. Pero esta analogía no es completa. En los modernos edificios de gran altura y emplazados en un buen sitio, se puede obtener mayor rentabilidad de los pisos superiores que de algunas de las plantas bajas. En efecto, los pisos altos son muy buscados para instalar en ellos apartamentos de lujo, despachos para los hombres de negocios y, algunas veces, restaurantes de gran categoría.

Zárate $(1992,111)$, se refiere a los intentos de delimitación del centro, en los que se han construido índices basados en la altura de los edificios, en la distribución de la población, en las características del empleo de las personas que trabajan en el CBD, en los flujos de tráfico de vehículos y peatones, y en los valores y usos del suelo. Para este autor, los índices que han alcanzado mayor fortuna son los que corresponden al denominado "Método índice del Centro de Negocios" elaborado por Murphy y Vance en 1954. Este método se fundamenta en la representación cartográfica de los usos del suelo y tiene la ventaja de apoyarse en datos de observación que permiten la fácil comparación entre los CBD de las diferentes ciudades (112).

Para algunos autores, hacer la distinción entre el área central y el CBD es más fácil en la teoría que en la práctica, y destacan para esta labor, la accesibilidad como el factor dominante.

Como resultado de la gran competencia por los mejores lugares del Centro de la ciudad los precios del suelo en estos puntos son muy elevados, y estos precios a su vez, han influido fuertemente sobre otras características de dicha zona. $\mathrm{La}$ más notable es la elevada densidad de utilización del suelo, que se refleja en la concentración de edificios de muchos pisos alrededor del área cuyos precios alcanzan los valores máximos; esto indica que se intenta lograr la máxima superficie de techo que permiten las leyes en estos sitios centrales tan valorados. Esto conduce a otorgar al centro de la ciudad una calidad tridimensional, que constituye otra de sus características más evidentes.

Dentro de las categorías de la construcción (residencial, para oficinas), el suelo, los inputs de los edificios, y el output no son en lo absoluto homogéneos. 
Existe una heterogeneidad en el suelo debido a sus características físicas (pendiente, propiedades de resistencia, drenaje). La heterogeneidad del suelo se debe también a la diferencia en cuanto a infraestructura. Las calles y los servicios pueden considerarse componentes de capital del suelo. Así pues, un estudio de Filadelfia indica que la obtención de acceso a los drenajes hace que se duplique el valor del suelo (Hoch, spi, 96).

El input de los edificios incluye los inputs de la construcción y los inputs de operación y mantenimiento, una vez que el edifico haya sido construido. Centenares de inputs se hayan implicados en la construcción y operación de los edificios de oficinas. Hasta sesenta operaciones están implicadas en la construcción de edificios de oficinas de elevada altura. En general se involucra un elevado grado de optimización a diversos niveles en la elección de los diseños, los materiales, los procesos y la mano de obra (97).

Pueden observarse ciertos costos específicos. A medida que aumenta la altura de un edifico, los costos de cimentación y los de las paredes y ventanas no aumentan proporcionalmente. Sin embargo los costos mecánicos del ascensor, del equipo especializado y los de programación aumentan a una tasa más que proporcional. Kingston y Clark (en Hoch, 98) presentan datos que muestran que los ascensores ocupan el $2 \%$ del espacio útil bruto de los edificios de 8 plantas, el $5 \%$ de los de 30 plantas y el $10 \%$ de los de 55 .

Las regulaciones de las zonas pueden clasificarse bajo dos encabezamientos principales: regulación del uso del suelo y regulación de la construcción. Estas últimas incluyen limitaciones sobre la altura de los edificios, el porcentaje de un solar que puede ser ocupado por una estructura, los escalonamientos y la regulación del espacio no edificado, y se basan en el supuesto de que el constructor no puede responder del acceso a la luz, al aire y a la vista, por su propia voluntad (Hoch, 100).

En 1966 hubo rechazo en NY de vivir en edificios de más de 8 pisos (no se querían formar ghettos verticales). Esto se debió a la creencia de que la elevada densidad conduce a un comportamiento antisocial, pero los desordenes sociales causados aparentemente por la densidad son causado en la realidad por la baja renta, la escasa educación y el aislamiento social.

Fitch (en Hoch, 142) afirma que es probable que la mitad superior de las futuras ciudades de rascacielos, sean áreas residenciales, la zona media institucional y la inferior comercial y fabril. En tal estructura urbana, el recorrido diario implicará un trayecto vertical de 30 pisos en lugar de un trayecto horizontal de varios kilómetros. 


\section{Metodología}

El estudio involucró las siguientes actividades:

- Definición del marco conceptual, variables relacionadas y definición operacional.

- Identificación y localización espacial de los edificios de cinco o más pisos por cada década. Se basa en trabajo de campo para la obtención del número de edificios de Medellín y de información factible de encontrar por observación directa del objeto de estudio y recopilación de la información existente en entidades del orden municipal. Esta información comprende textos, mapas y tablas en formato análogo y digital.

- Clasificación de los barrios según el número de edificios de más de cinco pisos que poseen.

- Establecimiento de indicadores y rangos para el levantamiento de capas de información requerida para la identificación de patrones y tendencias.

- Levantamiento de información a correlacionar, según el marco conceptual y metodológico.

- Análisis de correlación, análisis espacial e identificación de patrones y tendencias.

En los archivos de Planeación Metropolitana se encontró información del $71 \%$ de los edificios censados que cumplían la condición de tener cinco o más pisos. Los registros más antiguos son de mediados del siglo XX. La información que podía tener un edificio en particular, en dicha base de datos, era por lo general fragmentaria.

Los datos se organizaron por décadas pero se debe tener en cuenta que las memorias de registro y levantamiento de datos en la ciudad es relativamente reciente, por lo que se catalogó la información para que correspondiera al período antes de 1970 y las décadas de los años 1970, 1980 y 1990. Los análisis más destacados corresponden a los tres últimos lapsos, ya que son los que tiene mayor información disponible.

Los datos obtenidos en el censo dieron un total de 2.685 edificios existentes en Medellín, con 5 ó más pisos. Esta base de datos debió ser disminuida a 1.909 edificios, debido a que los restantes no contaban con la información en la oficina de Planeación Municipal que permitiera la elaboración posterior de tablas y figuras para el análisis.

La información se agrupó luego por barrios, número de pisos (por rango), área del lote (por rango), uso previo (por categorías), uso actual (categorías), número de pisos (por rango). En esta etapa la información fue nuevamente filtrada ya que para la unidad de barrio no se encontraron datos de valores para la variación en el tiempo de algunos parámetros como por ejemplo precio del suelo. Fue con este último conjunto con el que se llegó al proceso estadístico para la prueba de la hipótesis. 


\section{Variables}

A continuación se presentan las variables y sus características, escogidas para armar un modelo estadístico que intente explicar la influencia y el grado de importancia que tiene cada una en el hecho de que se construya o no un edificio en determinado barrio.

1. La renta del suelo: es de obligatoria inclusión por el peso que tiene en la construcción del espacio urbano dentro del sistema económico capitalista.

\section{La reglamentación sobre} construcción en altura: expresada básicamente por el índice de construcción o el número de pisos permitido. Es relativamente reciente y su aplicación en épocas anteriores era limitado sólo a algunas áreas de la ciudad en donde la realización de ciertas funciones críticas como las operaciones del aeropuerto y las telecomunicaciones obligaba a restringir el número de pisos o la altura de cualquier construcción. Solamente a partir de la expedición del POT se puede hablar de restricciones que se salen de esta motivación.

\section{El estrato socio-económico de la} zona: participa como polo de atracción de la actividad constructora. La edificación en altura está dirigido principalmente a clases sociales pudientes y así queda expresado en la teoría económica sobre la renta del suelo urbano.
4. El tamaño del predio: como característica influyente del suelo en el fenómeno, se ha tomado como factor que puede ser importante para definir las tendencias en la construcción de edificios. En las grandes ciudades ha ocurrido que uno de los medios utilizados para aumentar la ganancia utilizando la tierra como mercancía, ha sido el fraccionamiento de lotes de antiguos predios lo que puede disminuir las oportunidades de construcción en altura. Pero por otra parte, por especificaciones técnicas de los edificios de más de cuatro pisos, se seleccionan terrenos de cierto tamaño. Además, la reglamentación fija el índice de construcción teniendo en cuenta el tamaño del lote. A pesar de estos condicionantes, existen edificios que están construidos en lotes que no calificarían para tal fin.

5. Uso previo del predio: La siguiente característica tiene la intención de descubrir la preferencia de los constructores en la selección de los sitios, según se presenten como lotes solos o como construcciones antiguas. Aunque ya existen en nuestro medio, pocos lotes de los llamados "de engorde", estos pueden recibir una fuerte presión de los constructores ya que proporcionan mayores economías durante el proceso. Por otro lado, las medidas de renovación urbana no son muy frecuentes en nuestro medio y algunas construcciones de cierto valor cultural o el arraigo de los habitantes, pueden convertirse en cortapisa para esta acción. 
Modelo estadístico y matemático

La siguiente es la hipótesis de investigación planteada:

Las variables que explican la localización del fenómeno de redensificación en la ciudad de Medellín son:

La renta del suelo.

La reglamentación sobre el índice de construcción permitido.

El estrato socio-económico del barrio.

Área del predio.

Uso previo del predio.

Tal como se plantea, esta hipótesis es estadística de tipo causal multivariado y genera un modelo que puede expresarse como una regresión lineal múltiple del siguiente tipo:

$y=\mathrm{b}_{0}+\mathrm{b}_{1} x_{1}+\mathrm{b}_{2} x_{2}+\mathrm{b}_{3} x_{3}+\mathrm{b}_{4} x_{4}+$ $\mathrm{b}_{5} x_{5}+\mathrm{e}_{i}$

En donde:

$y$ : es la variable dependiente que expresa el número de edificios que es posible encontrar en un barrio, dadas ciertas características:

$x_{\mathrm{i}}$ : son las variables independientes y se discriminan así:

$x_{1}$ : representa la variable renta total del suelo. $x_{2}$ : se relaciona con la existencia o no de una restricción para la construcción en altura.

$x_{3}$ : representa la clasificación según el estrato socio - económico del barrio.

$x_{4}$ : está determinado por el tamaño del predio.

$x_{5}$ : expresa el uso previo del suelo.

$\mathrm{b}_{0}$ : representa al intercepto en la ecuación.

$b_{i}$ : son los coeficientes de regresión, parciales.

$\mathrm{e}_{i}$ : es el error de estimación.

Se plantean entonces las siguientes hipótesis estadísticas:

$H_{0}: \mathrm{b}_{1}=\mathrm{b}_{2}=\mathrm{b}_{3}=\mathrm{b}_{4}=\mathrm{b}_{5}=0$ Hipótesis nula: $y$ no depende linealmente de ninguna de las variables $x_{i}$

$H_{1}: \mathrm{b}_{1}{ }^{1} \mathrm{~b}_{2}{ }^{1} \mathrm{~b}_{3}{ }^{1} \mathrm{~b}_{4}{ }^{1} \mathrm{~b}_{5}{ }^{1} 0$ Hipótesis alterna: $y$ es linealmente dependiente de por lo menos una de las variables $x_{i}$

Se trabaja con los siguientes supuestos del modelo:

$\mathrm{e}_{i} \sim \mathrm{N}, \mathrm{I}\left(0, \mathrm{~s}^{2}\right)$

$y_{i} \sim \mathrm{N},\left(\mathrm{E}\left(Y_{i}\right), \mathrm{s}^{2}\right)$

Para la prueba de hipótesis se usará la prueba $\mathrm{F}$, con $\mathrm{a}=5 \%$. 
Sobre las tendencias en la redensificación del área urbana de Medellín, se acudirá a la dinámica histórico - espacial de la construcción de edificios. Sobre la existencia de patrones, existe un procedimiento gráfico propuesto por Gámir et al (1995, 41-56, 249-378), que se basa en "el empleo del análisis de vecindad $y$ se fundamenta en el reconocimiento de tres estructuras puntuales tipo, que se denominan con los términos de "concentrada", "aleatoria" y "dispersa"" (42). La estructura "concentrada" es aquella en la que existe una elevada densidad de puntos dentro de un área de estudio, mientras que en la "dispersa", la distribución de los puntos tiende a ocupar el mayor espacio posible (máxima distancia entre los puntos). La "aleatoria" se sitúa en un punto intermedio.

La técnica consiste en comparar entre la distancia media observada que existe entre cada punto y el más próximo a él y la distancia hipotética que existiría si estos puntos estuviesen distribuidos de forma aleatoria. La distribución aleatoria de los puntos se asemeja a una distribución normal. Debido a esto, el concepto de aleatoriedad no se circunscribe a un dato, sino que afecta a un rango cuya amplitud está determinada por el número de observaciones y por el grado de error que admitamos en el experimento (44). El análisis del vecino más próximo se calcula mediante la siguiente expresión:

$$
\begin{aligned}
& \text { do En donde: } \mathrm{R}(1) \text { : índice de vecindad para un elemento } \\
& \mathrm{R}(1)=\frac{-}{d a} \quad \begin{array}{ll}
d o: & \begin{array}{l}
\text { distancia media observada entre cada punto } \\
\text { y el más cercano. } \\
\text { distancia media entre cada punto y el más } \\
\text { cercano obtenida por un procedimiento aleatorio. }
\end{array}
\end{array}
\end{aligned}
$$

$d o$, se divide por el número de puntos que han sido objeto de estudio: $d o=\Sigma d o / n$. En este caso, $\Sigma d o$ es la suma de distancias observadas entre cada par de puntos, y $n$, número de puntos o de observaciones. La distancia media aleatoria se calcula mediante el empleo de la distribución aleatoria de Poisson, definida por:

$$
d_{a}=\frac{1}{2 * \sqrt{\frac{n}{a}}}
$$

En donde $a$ : superficie del área de estudio.

Si ambas distribuciones fuesen idénticas $d o=d a(\mathrm{R}(1)=1)$, en este caso se estaría frente a una estructura aleatoria. Si la distancia media observada fuese la más corta posible, al estar todos los puntos agrupados en un solo lugar $\mathrm{R}(1)=0$. Queda el caso en el que la distancia media observada fuese la máxima posible, se estaría frente a una distribución netamente dispersa, $R(1)=2.149$. 


\section{Resultados}

Los datos presentados en la tabla 1, corresponden a la matriz para el análisis de regresión múltiple mediante el cual se pretende demostrar la relación de los factores escogidos y el fenómeno de la construcción vertical en Medellín. Sobre los datos se deben hacer las siguientes consideraciones:

Tabla 1. Matriz para el análisis de regresión múltiple

\begin{tabular}{|c|c|c|c|c|c|c|}
\hline Década del 70 & \multirow{2}{*}{$\begin{array}{c}\text { Estrato } \\
\text { del barrio } \\
\text { promedio } \\
\end{array}$} & \multirow{2}{*}{$\begin{array}{c}\text { No. } \\
\text { Edificios/ } \\
\text { década }\end{array}$} & \multirow{2}{*}{$\begin{array}{c}\text { Precio } \\
\text { promedio } \\
\text { del suelo } \\
\end{array}$} & \multirow{2}{*}{$\begin{array}{c}\text { Restricción } \\
\text { de } \\
\text { altura } \\
\end{array}$} & \multirow{2}{*}{$\begin{array}{c}\text { Área } \\
\text { promedio } \\
\text { del predio }\end{array}$} & \multirow{2}{*}{$\begin{array}{c}\text { Uso } \\
\text { previo } \\
\text { promedio } \\
\end{array}$} \\
\hline Barrio & & & & & & \\
\hline ASTORGA & 5 & 1 & 238292 & 2 & 2546.34 & 2 \\
\hline CONQUISTADORES & 5 & 25 & 406776 & 2 & 661.63 & 2 \\
\hline EL VELODROMO & 5 & 4 & 333609 & 2 & 244.38 & 2 \\
\hline ESTADIO & 5 & 5 & 333609 & 2 & 963.41 & 2 \\
\hline FLORIDA NUEVA & 4 & 5 & 333609 & 2 & 615.54 & 2 \\
\hline LA CASTELLANA & 5 & 5 & 318400 & 2 & 793.36 & 2 \\
\hline LAURELES & 5 & 13 & 406776 & 2 & 637.08 & 1 \\
\hline ROSALES & 4 & 4 & 250936 & 2 & 662.24 & 2 \\
\hline SIMON BOLIVAR & 5 & 4 & 318400 & 2 & 688 & 2 \\
\hline SURAMERICANA & 5 & 8 & 492278 & 1 & 1599.13 & 2 \\
\hline Década del 80 & \multirow{2}{*}{$\begin{array}{c}\text { Estrato } \\
\text { del barrio } \\
\text { promedio }\end{array}$} & \multirow{2}{*}{$\begin{array}{c}\text { No. } \\
\text { Edificios/ } \\
\text { década }\end{array}$} & \multirow{2}{*}{$\begin{array}{c}\text { Precio } \\
\text { promedio } \\
\text { del suelo }\end{array}$} & \multirow{2}{*}{$\begin{array}{c}\text { Restricción } \\
\text { de } \\
\text { altura } \\
\end{array}$} & \multirow{2}{*}{$\begin{array}{c}\text { Área } \\
\text { promedio } \\
\text { del predio }\end{array}$} & \multirow{2}{*}{$\begin{array}{c}\text { Uso } \\
\text { previo } \\
\text { promedio }\end{array}$} \\
\hline Barrio & & & & & & \\
\hline ASTORGA & 5 & 2 & 343200 & 2 & 514.9 & 2 \\
\hline CONQUISTADORES & 5 & 29 & 378400 & 2 & 679.43 & 2 \\
\hline EL VELODROMO & 5 & 10 & 234000 & 2 & 408.86 & 2 \\
\hline ESTADIO & 5 & 9 & 234000 & 2 & 866.64 & 2 \\
\hline FLORIDA NUEVA & 4 & 18 & 234000 & 2 & 452.13 & 2 \\
\hline LA CASTELLANA & 5 & 12 & 267512 & 2 & 572.59 & 2 \\
\hline LAURELES & 5 & 69 & 481600 & 2 & 473.99 & 1 \\
\hline ROSALES & 4 & 5 & 260920 & 2 & 821.65 & 2 \\
\hline SIMON BOLIVAR & 5 & 11 & 267512 & 2 & 334.25 & 2 \\
\hline SURAMERICANA & 5 & 3 & 344000 & 1 & 284.85 & 2 \\
\hline Década del 90 & \multirow{2}{*}{$\begin{array}{c}\text { Estrato } \\
\text { del barrio } \\
\text { promedio }\end{array}$} & \multirow{2}{*}{$\begin{array}{c}\text { No. } \\
\text { Edificios/ } \\
\text { década }\end{array}$} & \multirow{2}{*}{$\begin{array}{c}\text { Precio } \\
\text { promedio } \\
\text { del suelo }\end{array}$} & \multirow{2}{*}{$\begin{array}{c}\text { Restricción } \\
\text { de } \\
\text { altura }\end{array}$} & \multirow{2}{*}{$\begin{array}{c}\text { Área } \\
\text { promedio } \\
\text { del predio }\end{array}$} & \multirow{2}{*}{$\begin{array}{c}\text { Uso } \\
\text { previo } \\
\text { promedio }\end{array}$} \\
\hline Barrio & & & & & & \\
\hline ASTORGA & 5 & 7 & 470000 & 2 & 1756.63 & 1 \\
\hline CONQUISTADORES & 5 & 37 & 391000 & 2 & 480.28 & 1 \\
\hline EL VELODROMO & 5 & 9 & 408000 & 2 & 348.83 & 2 \\
\hline ESTADIO & 5 & 14 & 408000 & 2 & 357.26 & 2 \\
\hline FLORIDA NUEVA & 4 & 8 & 408000 & 2 & 551.84 & 2 \\
\hline LA CASTELLANA & 5 & 42 & 358333 & 2 & 355.33 & 2 \\
\hline LAURELES & 5 & 57 & 505000 & 2 & 555.5 & 2 \\
\hline ROSALES & 4 & 5 & 304000 & 2 & 253.39 & 2 \\
\hline SIMON BOLIVAR & 5 & 8 & 358333 & 2 & 287.99 & 2 \\
\hline SURAMERICANA & 5 & 9 & 423000 & 1 & 1445.61 & 2 \\
\hline
\end{tabular}


Son los resultantes de una selección de variable por variable en donde han quedado eliminados aquellos que no tenían información que permitiese el procesamiento estadístico.

Los barrios remanentes después de la selección, son representativos de las diferentes características y variables escogidas, lo que beneficia la heterogeneidad de la matriz de datos.

Con el somero conocimiento que se tenía del fenómeno del crecimiento vertical en Medellín, se intentó crear un modelo estadístico predictivo que permitiera por un lado, establecer los niveles en que las variables seleccionadas han influido para que en determinados barrios haya una fuerte presencia de desarrollos constructivos en altura y en otros no, y de otro lado, establecer un modelo que permitiera, dados los valores que dichas variables tomaban en un barrio específico, predecir el número de edificios que posiblemente se construirían en dicha unidad espacial. El procesamiento y adquisición de la información concerniente a dichas variables y las consideraciones tenidas en cuenta, se pone de manifiesto a continuación.

\section{Número de edificios}

Esta variable fue medida en el campo, haciendo un cubrimiento de toda la ciudad de Medellín y considerando como criterio "tener cinco o más pisos de altura". Adicionalmente se tomaron algunos apuntes de campo relacionados con el uso general, usos de los primeros pisos, existencia de parqueaderos, nomenclatura, nombre del edificio.

Mediante este procedimiento se levantó información básica de 2685 edificios que estaban distribuidos en 133 barrios de los 249 que tiene la ciudad. Luego en consulta de los archivos de la Secretaría de Planeación Metropolitana, se completó la información requerida para los edificios que estaban incluidos en el sistema de esta entidad. Resultante de este proceso aparecen 1909 edificios en 121 barrios, con información que aún resulta incompleta al no existir datos de algunas variables.

Se logra obtener una matriz de información cuyo encabezamiento es como lo muestra la tabla 2. 
Tabla 2

Matriz de información obtenida en campo

\begin{tabular}{|l|l|}
\hline BARRIO & LONGITUD FRENTE \\
\hline COMUNA & AREA LOTE \\
\hline ESTRATO & AREA CONSTRUIDA \\
\hline CIRCULAR & ÍNDICE DE CONSTRUCCIÓN (I.C.) \\
\hline TRANSVERSAL & NÚMERO DE SÓTANOS \\
\hline DIAGONAL & USO PREVIO DEL LOTE \\
\hline CALLE & USO DEL EDIFICIO \\
\hline CARRERA & USO DEL SOTANO \\
\hline NÚMERO & NÚMERO DE TORRES \\
\hline NOMBRE & USO 1er PISO \\
\hline PISOS CONTADOS & USO 2o PISO \\
\hline PISOS LICENCIA & USO 3er PISO \\
\hline AÑO CONSTRUCCIÓN & COMENTARIOS \\
\hline
\end{tabular}

El tratamiento de la base de datos permitió cuantificar el número de edificios que tenía cada barrio a la fecha del estudio (año 1.999), ilustrado en la figura 5.

\section{Precio promedio del suelo}

Se asignó con base en el estudio de La Lonja de Propiedad Raíz de Medellín y el Valle de Aburrá, hecho en 1999. Esta información resultó ser un nuevo filtro de los datos ya que el estudio y la información facilitada por dicha entidad no permitió asignar precio del suelo a todos los barrios. De ahí que, considerando que esta investigación es multitemporal ya que plantea variaciones para las décadas del 70, 80 y 90 , los barrios que cumplían con estas condiciones fueron 10 aunque para cada década hubiera más. Esta información permitió elaborar la figura 6 de precios del suelo para el año 1999 en unidades de pesos $/ \mathrm{m}^{2}$.

\section{Restricciones de altura}

Las referencias que se tenían de esta variable eran solamente textuales y mencionaban tres zonas de la ciudad con restricción para construir edificios: el cono del aeropuerto Olaya Herrera, el cono de Telecom y el cerro Nutibara. Con el advenimiento del Plan de Ordenamiento Territorial de Medellín, y consultando las restricciones para los 10 barrios mencionados, se obtuvo la información necesaria para el análisis estadístico. Esta variable se asignó teniendo en cuenta únicamente si había restricción o no, casos en los cuales se daba al barrio un valor de 1 ó 2 respectivamente. 
Figura 5

Fuente: Trabajo de Campo.

86 Fabio de Jesús Vélez Macías

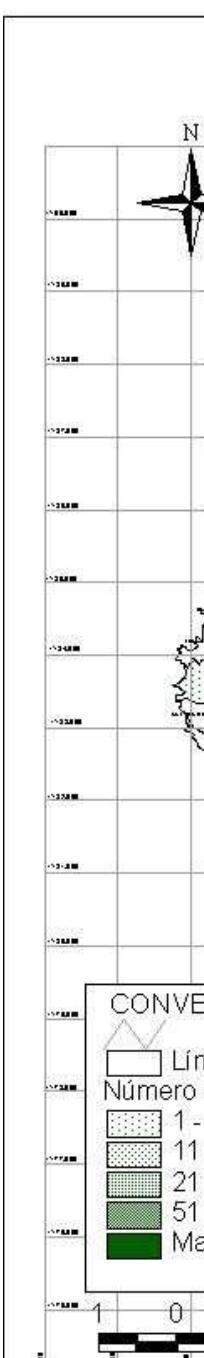




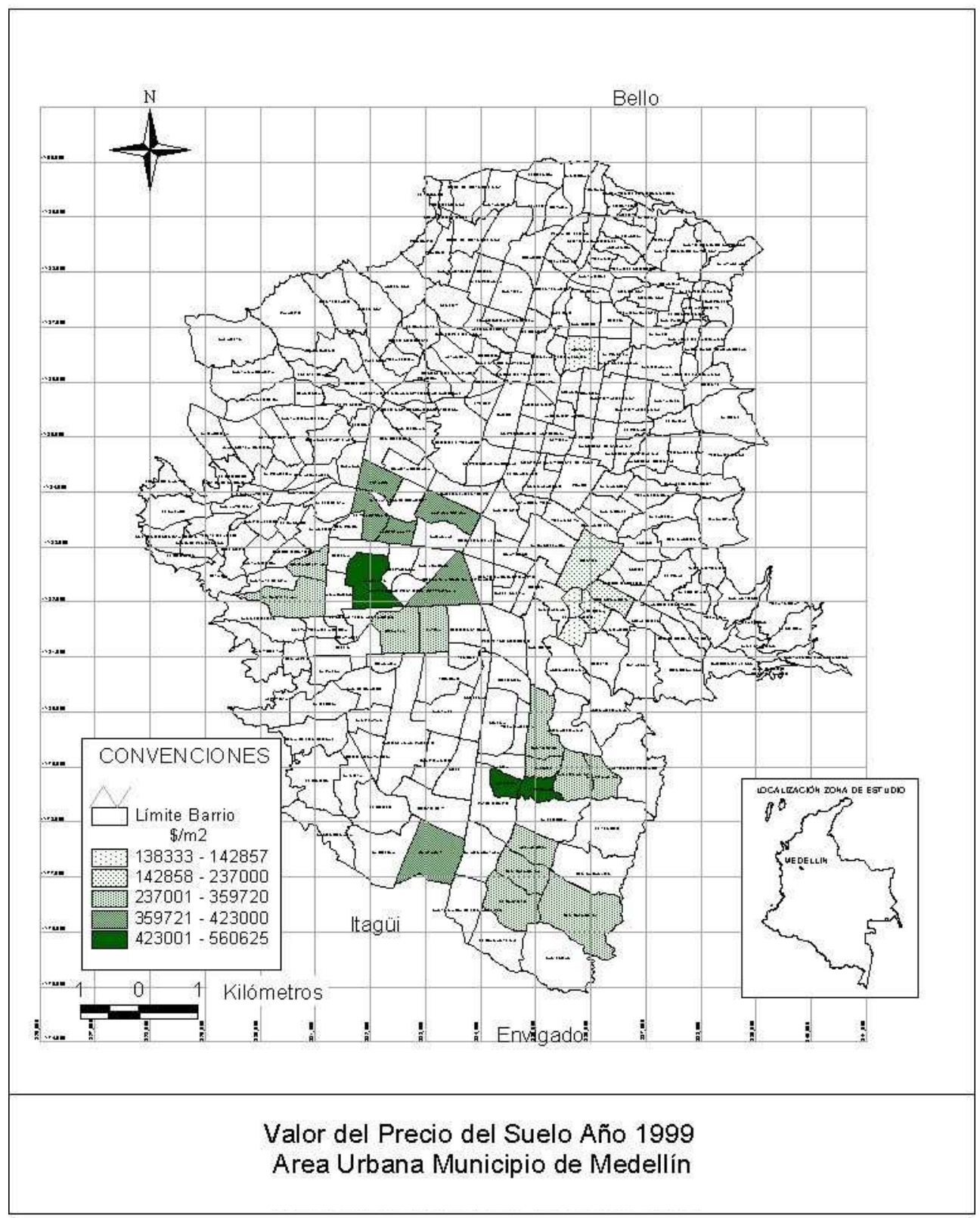

Figura 6

Fuente: La Lonja de Propiedad Raíz. 


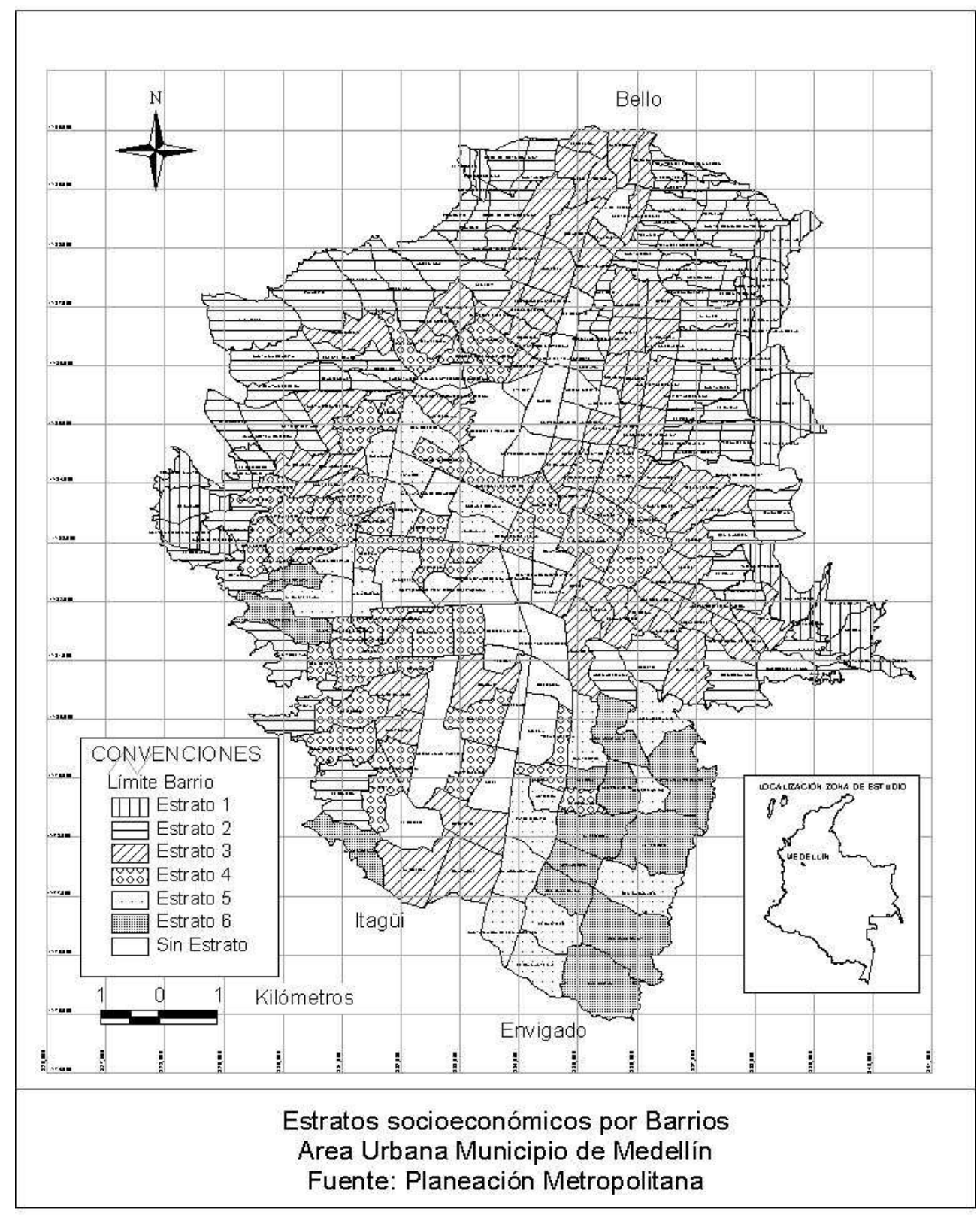

Figura 7

Fuente: Planeación Metropolitana.

88 Fabio de Jesús Vélez Macías 


\section{Estrato socio-económico del barrio}

Esta información fue obtenida en la biblioteca de la misma Secretaría de Planeación Metropolitana y consignada en la matriz anterior. Como es sabido, sus valores oscilan entre 1 y 6 . La representación gráfica se presenta en la figura 7.

\section{Área promedio del predio}

Resultó del tratamiento estadístico de esta variable, aplicado al conjunto de datos de cada barrio. Su valor se referencia en $\mathrm{m}^{2}$.

En la figura 8 se presenta una distribución de los edificios por barrios para ver con mayor claridad, que son más los barrios que cuentan con unos pocos edificios y que solamente 2 tienen entre 201 y 250 edificios: la Candelaria y Laureles, con la base de datos de 2685 registros. El número de edificios por barrio se presenta en la tabla 3, en donde están agrupados los edificios por rangos. En este caso la base utilizada es la de 1909 edificios. Los barrios de la figura 8 se listan en la tabla 4.

Los datos del censo de edificios aportan varias miradas al fenómeno del crecimiento vertical en la ciudad de Medellín. Uno de ellos es su dinámica en el tiempo en donde se pueden observar las fluctuaciones cíclicas que son comparables con las reportadas con la Lonja de Propiedad raíz de Medellín y con causas ya explicadas.
La tabla 5 muestra los datos obtenidos y a continuación la figura 9 proporciona una mejor imagen del fenómeno.

Con la información del estudio de La Lonja (1999), se genera la figura 10 sobre el ciclo de la construcción en Medellín que se ajusta en forma significativa a los datos obtenidos del censo de edificios, para el lapso 1970 y 1999. Vale la pena destacar que en ambas figuras coincide una recesión de las tasas de crecimiento de la construcción en altura, hacia finales de 2000.

Las variaciones en la aparición de nuevos edificios en algunos de los barrios más representativos de la ciudad, por su estrato socio - económico y la destinación de uso, se presenta en las siguientes figuras (11 a 14). El comportamiento individual de estos barrios es similar al general, salvo escasas situaciones que serán advertidas.

Por ejemplo, se puede observar como el comportamiento en la aparición de nuevos edificios a finales de los noventa refleja la parálisis de este sector en el año 2000 debida a la crisis económica y la fuga de capitales que antes eran invertidos en el sector de la construcción.

En la figura 13 se puede observar como a pesar de que los barrios Estadio y Velódromo son vecinos y presentan características similares en su conformación, el ciclo de la construcción de edificios no es coincidente. Esto se explica por una parte, porque el barrio Estadio inicio antes que el Velódromo el 
Tabla 3. Número de edificios por barrio

\begin{tabular}{|c|c|c|c|c|c|c|c|}
\hline BARRIO & $\begin{array}{c}\text { No. } \\
\text { Edif. }\end{array}$ & BARRIO & $\begin{array}{c}\text { No. } \\
\text { Edif. }\end{array}$ & BARRIO & $\begin{array}{c}\text { No. } \\
\text { Edif. }\end{array}$ & SAN BENITO & 22 \\
\hline $\begin{array}{l}\text { ALEJANDRO } \\
\text { ECHAVARRIA }\end{array}$ & 1 & ALTAMIRA & 3 & MIRAFLORES & 8 & EL VELODROMO & 24 \\
\hline ALTAVISTA & 1 & BOSQUES DE SAN PABLO & 3 & FERRINI & 9 & SAN JOAQUIN & 24 \\
\hline BELENCITO & 1 & CAMPO ALEGRE & 3 & LOS BALSOS N.2 & 9 & SURAMERICANA & 24 \\
\hline BETANIA & 1 & CENTROADMINISTRATIVO & 3 & PRADO & 9 & LOS COLORES & 25 \\
\hline $\begin{array}{l}\text { DIEGO } \\
\text { ECHAVARRIA }\end{array}$ & 1 & CORAZON DE JESUS & 3 & SANTA MONICA & 9 & PATIO BONITO & 25 \\
\hline EL DIAMANTE & 1 & LOS ALCAZARES & 3 & ASTORGA & 10 & Sta. Ma de los ANGLS & 25 \\
\hline EL SALADO & 1 & MIRAVALLE & 3 & EL CASTILLO & 10 & LAS LOMAS N.1 & 26 \\
\hline GERONA & 1 & SAN JAVIER N.2 & 3 & FATIMA & 10 & SIMON BOLIVAR & 26 \\
\hline GUAYABAL & 1 & VILLA HERMOSA & 3 & ASOMADERA N.2 & 11 & CALASANZ & 27 \\
\hline LA PRADERA & 1 & ARANJUEZ & 4 & LA PALMA & 11 & CASTROPOL & 27 \\
\hline LAS PALMAS & 1 & CRISTO REY & 4 & LOS ALPES & 11 & LAS LOMAS N.2 & 27 \\
\hline LORETO & 1 & MANRIQUE CENTRAL N.2 & 4 & NARANJAL & 11 & VILLA NUEVA & 28 \\
\hline $\begin{array}{l}\text { LUIS LOPEZ } \\
\text { DE MESA }\end{array}$ & 1 & PERPETUO SOCORRO & 4 & SAN JAVIER N.1 & 11 & FLORIDA NUEVA & 31 \\
\hline $\begin{array}{l}\text { MANRIQUE } \\
\text { CENTRAL N.1 }\end{array}$ & 1 & CERRO NUTIBARA & 5 & LOS BALSOS N.1 & 12 & LA FLORIDA & 32 \\
\hline NOEL & 1 & COLOMBIA & 5 & LOS PINOS & 12 & ESTADIO & 34 \\
\hline PILARICA & 1 & PARQUE JUAN PABLO II & 5 & COLON & 13 & EL DIAMANTE N.2 & 36 \\
\hline ROBLEDO & 1 & CATALUNA & 6 & EL POBLADO & 13 & LORENA & 36 \\
\hline SANTANDER & 1 & GRANADA & 6 & LA AGUACATALA & 13 & SANTATERESITA & 36 \\
\hline SIMESA & 1 & LA MOTA & 6 & SAN DIEGO & 13 & SAN LUCAS & 38 \\
\hline SUCRE & 1 & MANILA & 6 & ROSALES & 15 & EL TESORO & 39 \\
\hline U.D.A. GIRARDOT & 1 & NUEVA VILLA DE ABURRA & 6 & B. CRISTOBAL & 16 & LA AMERICA & 41 \\
\hline $\begin{array}{l}\text { BELLO } \\
\text { HORIZONTE }\end{array}$ & 2 & SAN MIGUEL & 6 & BELEN & 16 & BOLIVARIANA & 42 \\
\hline $\begin{array}{l}\text { CALASANZ } \\
\text { PARTE ALTA }\end{array}$ & 2 & VILLA CARLOTA & 6 & EL DANUBIO & 16 & BOSTON & 55 \\
\hline LA ALPUJARRA & 2 & CALLE NUEVA & 7 & CUARTA BRIGADA & 17 & LA CASTELLANA & 61 \\
\hline LA COLINA & 2 & EL RINCON & 7 & LALINDE & 18 & LAS ACACIAS & 76 \\
\hline PALENQUE & 2 & SANTA LUCIA & 7 & LOS ANGELES & 19 & CONQUISTADORES & 105 \\
\hline SAN BERNARDO & 2 & ESTACION VILLA & 8 & GUAYAQUIL & 20 & LA CANDELARIA & 138 \\
\hline SAN GERMAN & 2 & JESUS NAZARENO & 8 & LA FLORESTA & 20 & LAURELES & 147 \\
\hline VILLA FLORA & 2 & LOS NARANJOS & 8 & $\begin{array}{l}\text { EL NOGAL - } \\
\text { LOS ALMENDROS }\end{array}$ & 22 & TOTAL & 1909 \\
\hline
\end{tabular}

Fuente: trabajo de campo

90 Fabio de Jesús Vélez Macías 


\section{Tabla 4}

\section{Distribución de los edificios por barrios}

\begin{tabular}{|c|c|}
\hline $\begin{array}{l}\text { Rango de } \\
\text { edificios }\end{array}$ & BARRIOS \\
\hline 1 a 10 & $\begin{array}{l}\text { Alejandro Echavarría, Altavista, Belencito, Betania, Diego Echavarría, E1 } \\
\text { Diamante, El Salado, Gerona, Guayabal, La Pradera, Las Palmas, Loreto, Luis López } \\
\text { de Mesa, Manrique central n.1, Noel, Pilarica, Robledo, Santander, Simesa, Sucre, U. } \\
\text { D. Atanasio Girardot, Bello Horizonte, Buenos Aires, Calasanz parte alta, La Alpujarra, } \\
\text { La Colina, Palenque, San Bernardo, San Germán, Villa Flora, Altamira, Bosques de } \\
\text { San Pablo, Campo Alegre, Centro Administrativo, Corazon de Jesús, Los Alcazares, } \\
\text { Miravalle, San Javier n.2, Villa Hermosa, Aranjuez, Cristo Rey, Manrique central n.2, } \\
\text { Perpetuo Socorro, Cerro Nutibara, Colombia, Las Mercedes, Parque Juan Pablo II, } \\
\text { Cataluña, Granada, La Mota, Manila, Nueva Villa de Aburrá, San Miguel, Villa Carlota, } \\
\text { Calle Nueva, El Rincon, Santa Lucia, Estacion Villa, Jesús Nazareno, Los Naranjos, } \\
\text { Miraflores, Ferrini, Los Balsos n.2, Prado, Santa Monica, Astorga, El Castillo, Fatima, } \\
\text { Loma de los Bernal }\end{array}$ \\
\hline 11 a 20 & $\begin{array}{l}\text { Asomadera n.2, La Palma, Los Alpes, Naranjal, San Javier n.1, Los Balsos n.1, Los } \\
\text { Pinos, Colón, El Poblado, La Aguacatala, San Diego, Rosales, Barrio Cristobal, Belén, } \\
\text { El Danubio, Cuarta Brigada, Lalinde, Carlos E. Restrepo, Los Ángeles, Guayaquil, La } \\
\text { Floresta }\end{array}$ \\
\hline 21 a 50 & $\begin{array}{l}\text { El Nogal - Los Almendros, San Benito, El Velodromo, San Joaquin, Suramericana, Los } \\
\text { Colores, Patio Bonito, Santa María de los Ángeles, Las Lomas n.1, Simón Bolivar, } \\
\text { Calasanz, Castropol, Las Lomas n.2, Villa Nueva, Alejandria, Florida Nueva, La } \\
\text { Florida, Estadio, El Diamante n.2, Lorena, Santa Teresita, San Lucas, El Tesoro, La } \\
\text { América, Bolivariana }\end{array}$ \\
\hline 51 a 100 & Boston, La Castellana, Las Acacias \\
\hline 101 a 150 & Conquistadores, La Candelaria, Laureles \\
\hline
\end{tabular}




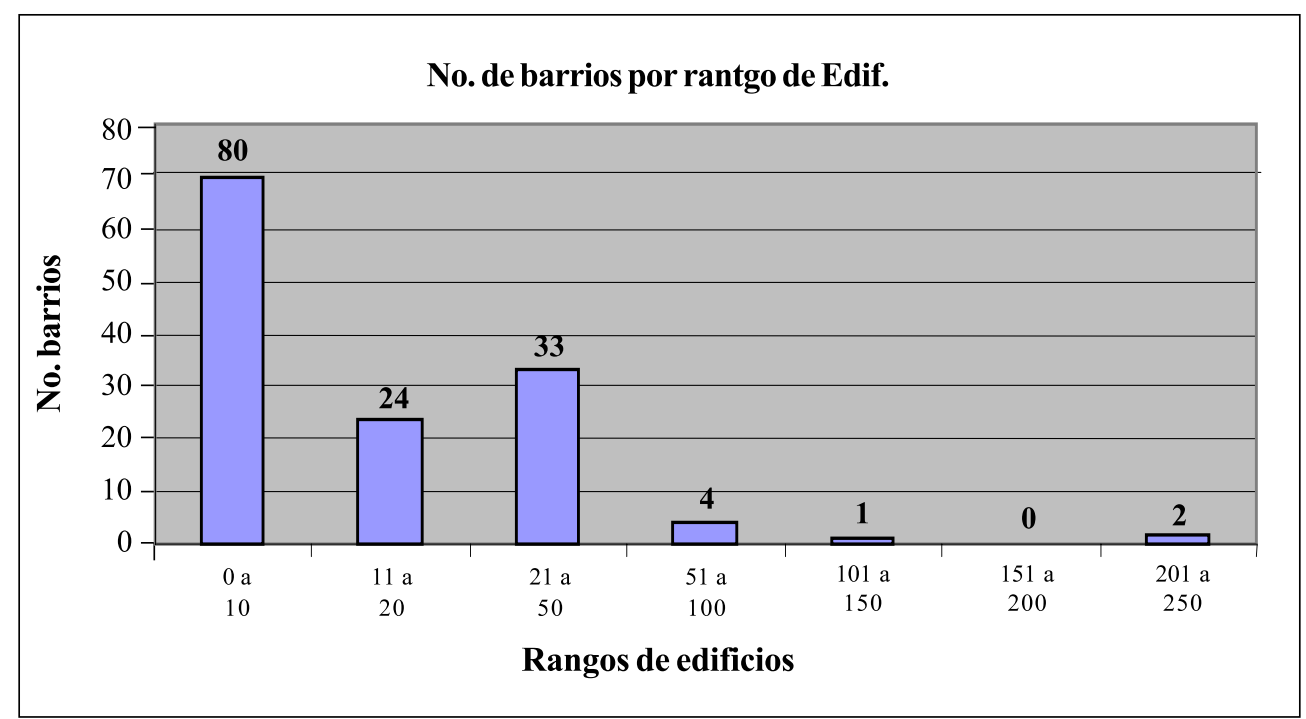

Figura 8

Tabla 5

Edificios construidos por año, en Medellín.

\begin{tabular}{|c|c|c|c|c|c|c|c|}
\hline Año & $\begin{array}{c}\text { No de } \\
\text { Edificios }\end{array}$ & Año & $\begin{array}{c}\text { No. de } \\
\text { Edificios }\end{array}$ & Año & $\begin{array}{c}\text { No. de } \\
\text { Edificios }\end{array}$ & Año & $\begin{array}{c}\text { No. de } \\
\text { Edificios }\end{array}$ \\
\hline 1941 & 1 & 1962 & 10 & 1974 & 16 & 1987 & 91 \\
1946 & 3 & 1963 & 15 & 1976 & 17 & 1988 & 97 \\
1950 & 2 & 1964 & 21 & 1977 & 41 & 1990 & 34 \\
1951 & 3 & 1965 & 18 & 1978 & 54 & 1991 & 49 \\
1953 & 1 & 1966 & 13 & 1979 & 41 & 1992 & 117 \\
1954 & 5 & 1967 & 7 & 1980 & 53 & 1993 & 149 \\
1955 & 4 & 1968 & 18 & 1981 & 69 & 1994 & 150 \\
1956 & 6 & 1969 & 13 & 1982 & 56 & 1995 & 97 \\
1957 & 1 & 1970 & 21 & 1983 & 37 & 1996 & 73 \\
1958 & 1 & 1971 & 29 & 1984 & 42 & 1997 & 81 \\
1959 & 3 & 1972 & 18 & 1985 & 67 & 1998 & 44 \\
1960 & 17 & 1973 & 13 & 1986 & 105 & 1999 & 7 \\
\hline
\end{tabular}

Fuente: trabajo de campo.

92 Fabio de Jesús Vélez Macías 


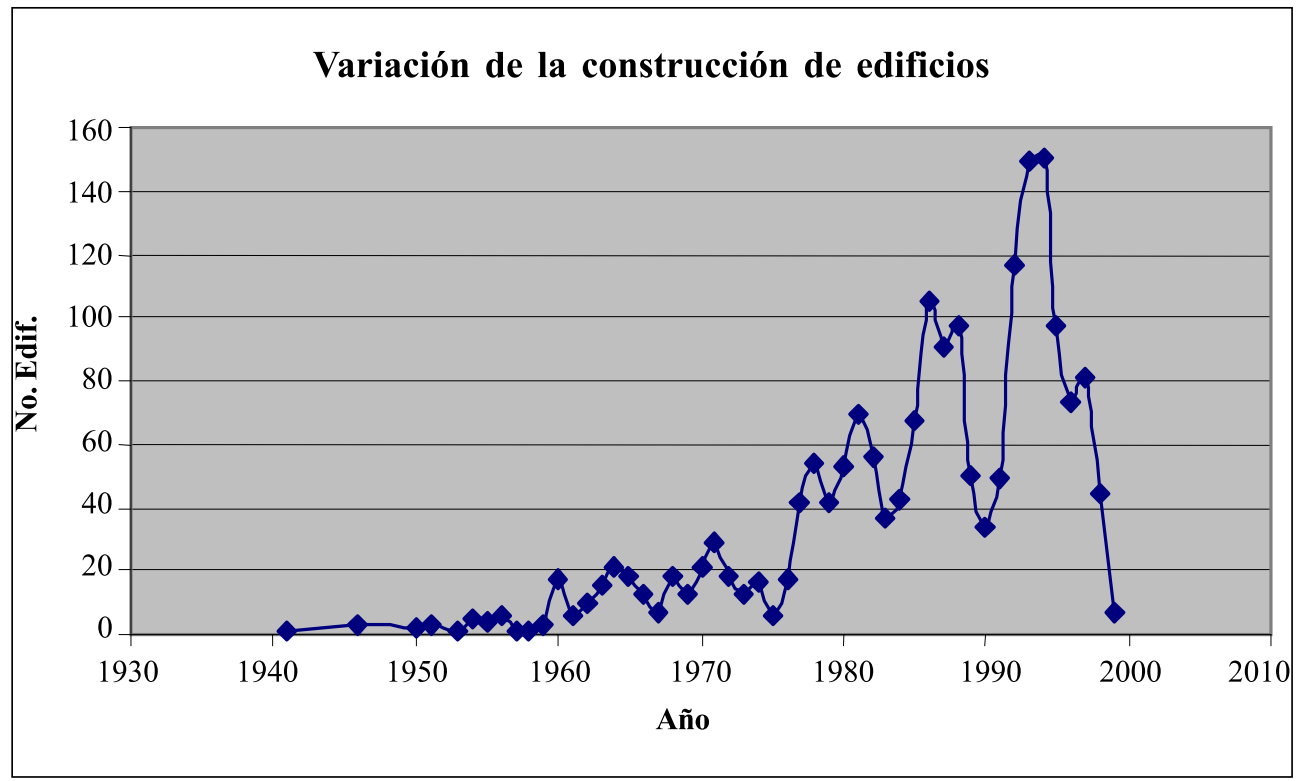

Fuente: Trabajo de campo.

Figura 9.

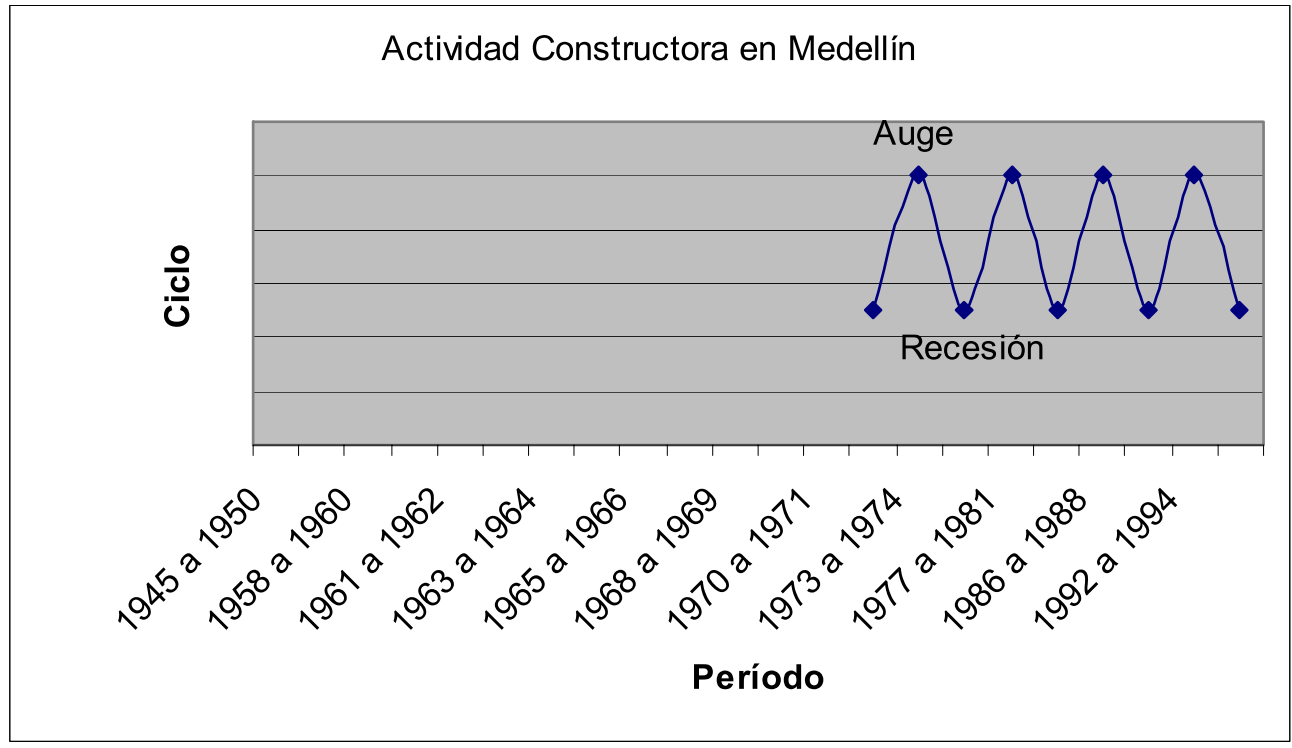

Fuente: La Lonja de Propiedad Raíz.

Figura 10. Ciclos de la actividad constructora en Medellín. 

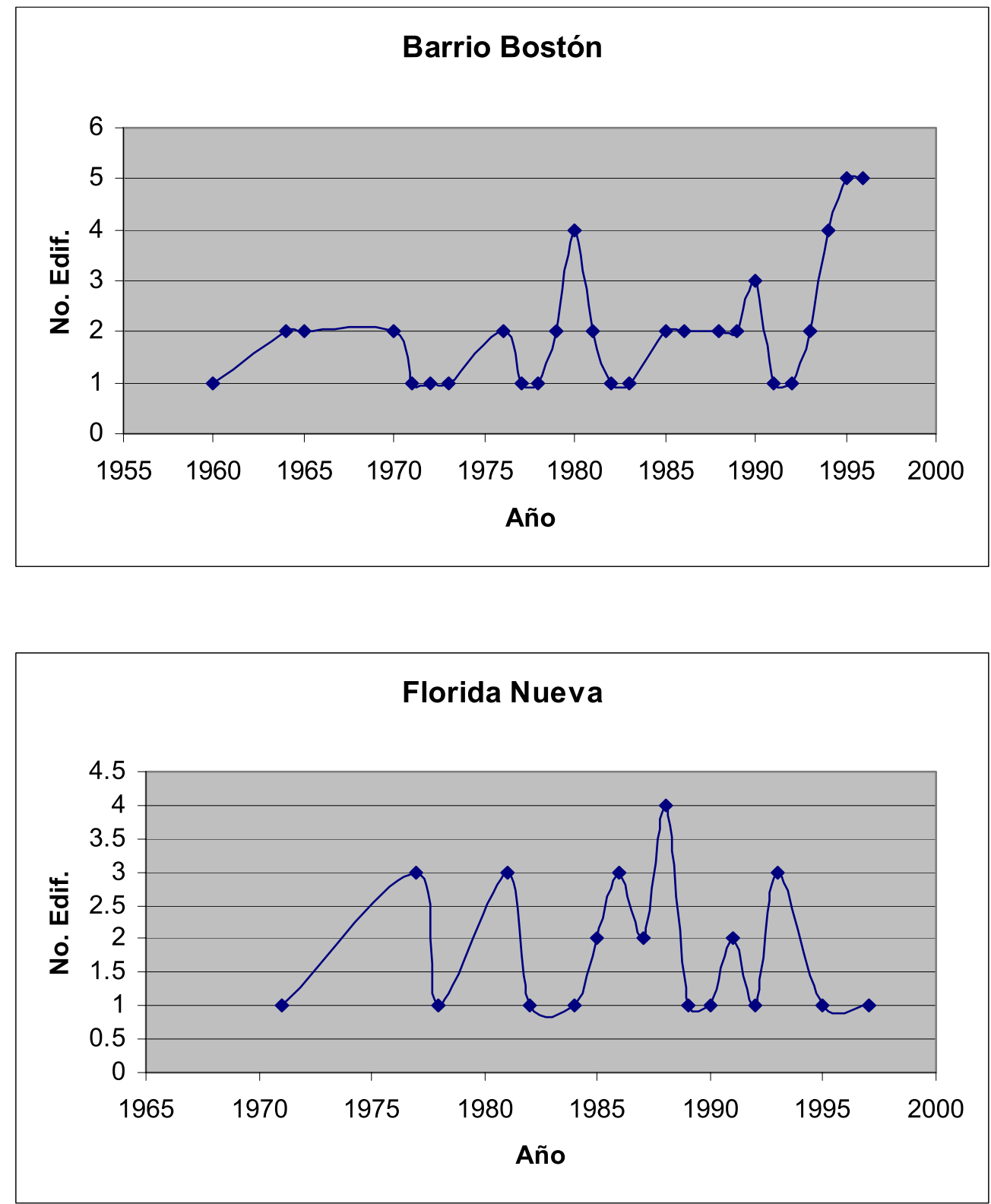

Fuente: Trabajo de campo.

\section{Figura 11.}

94 Fabio de Jesús Vélez Macías 

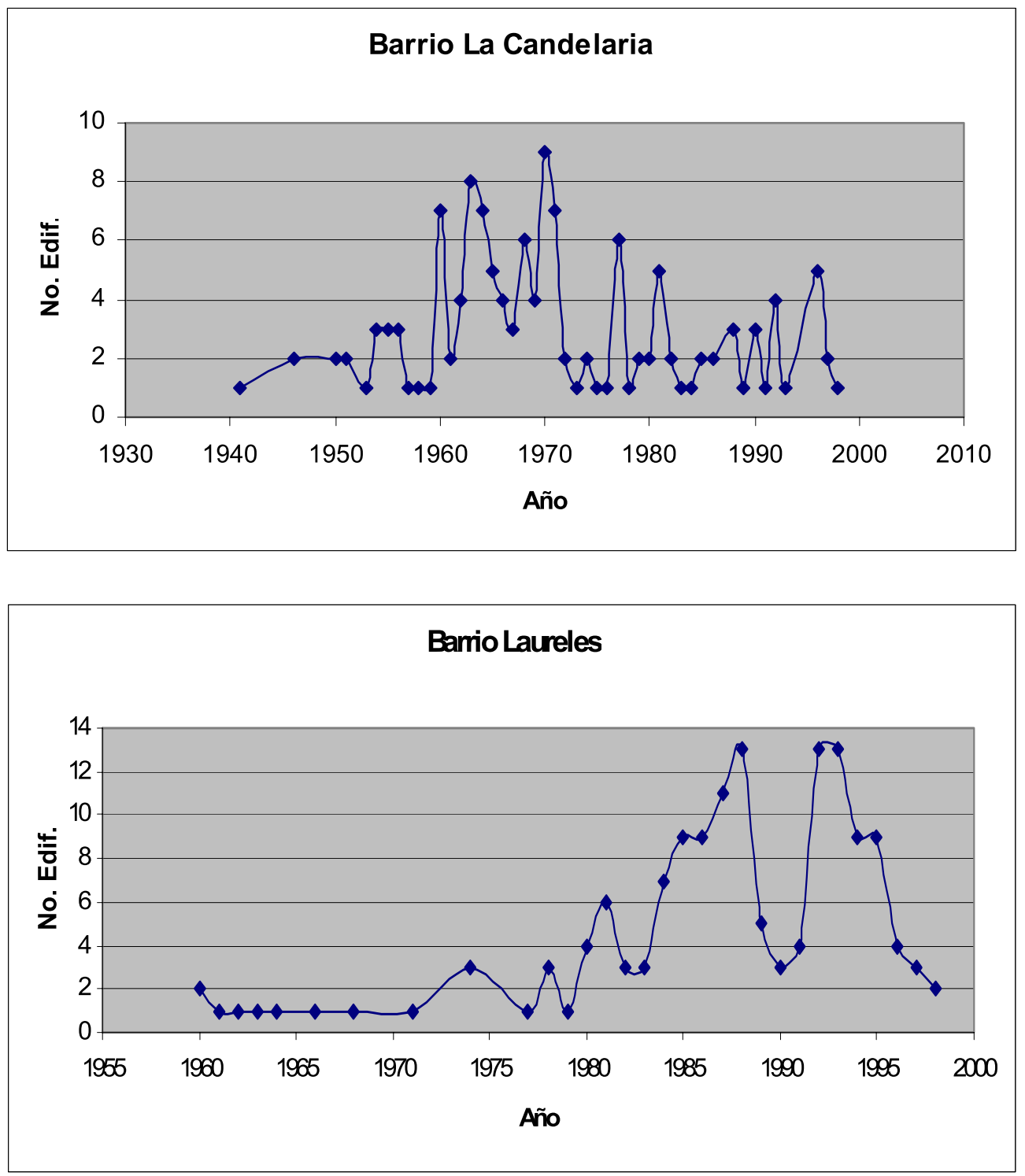

Fuente: Trabajo de campo.

Figura 12.

Perspectiva Geográfica 95 

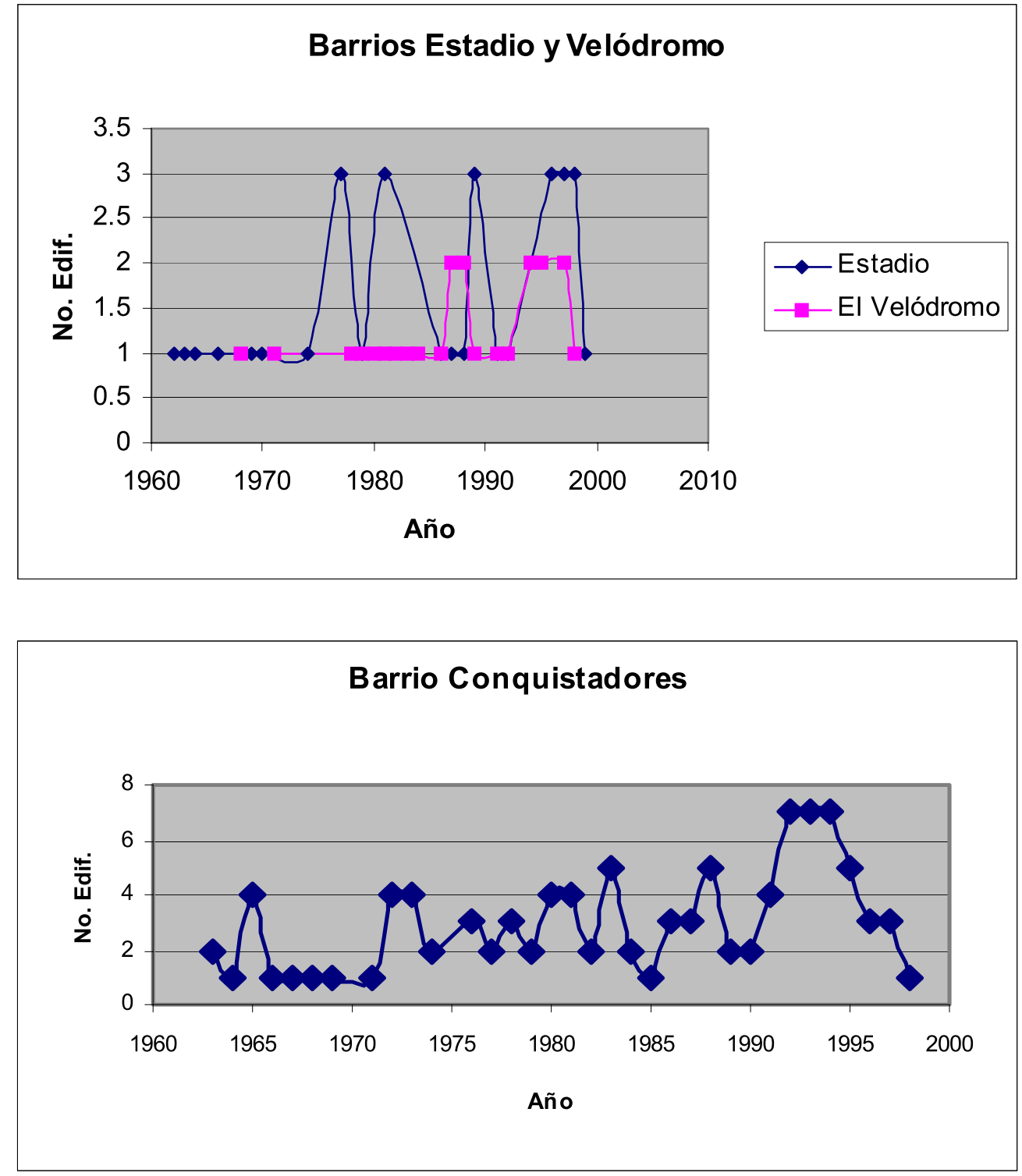

Fuente: Trabajo de campo.

\section{Figura 13.}

96 Fabio de Jesús Vélez Macías 

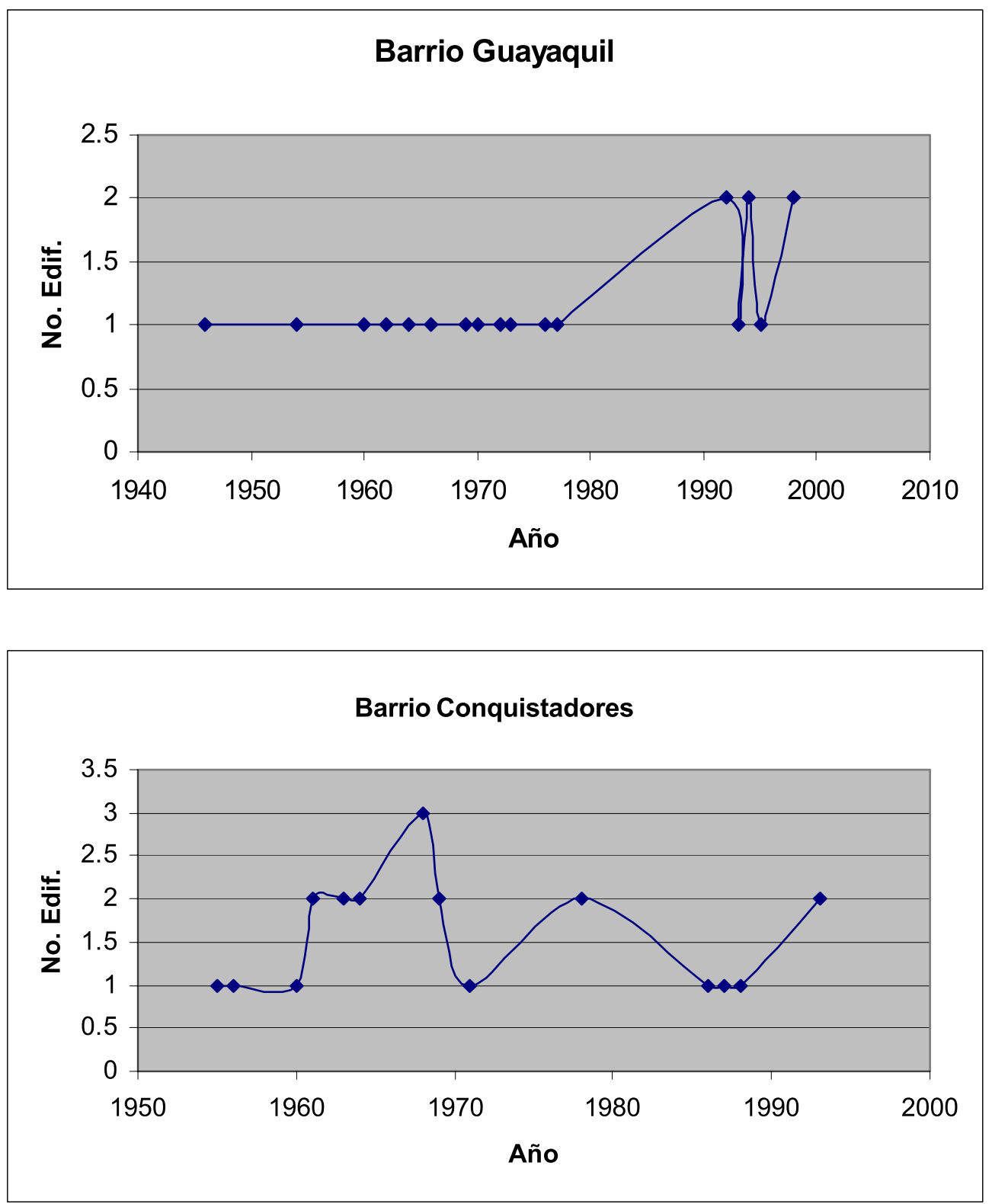

Fuente: Trabajo de campo.

Figura 14. 
proceso de construcción en altura. De otro lado, en dicho barrio se presenta un uso combinado del suelo entre residencial y comercial, lo que se convierte en un atractivo para ese tipo de construcción, mientras que el Velódromo es un barrio residencial más tradicional y con algunos usos institucionales.

En el caso del barrio Guayaquil, resalta el hecho de que la actividad constructora no siguió el ciclo de recesión que se debió presentar a fines de la década del 90, sino que por el contrario, en este barrio estaba en auge. Se puede dar como explicación el efecto del viaducto del Metro sobre la zona que generó una dinámica de renovación urbana, y el cambio de uso del suelo a uno más institucional y comercial ya que allí se sitúa el Centro Administrativo La Alpujarra y varios almacenes especializados.
El barrio San Benito, siendo uno de los barrios más antiguos de la ciudad, conserva una dinámica continua en la construcción de edificios, y a diferencia de otras zonas de la ciudad, aún existen construcciones con fechas más lejanas del inventario de Medellín.

Los comportamientos más ceñidos a los ciclos de la construcción son los de los barrios con mayor número de edificios: $\mathrm{La}$ Candelaria, Laureles y Conquistadores.

\section{Variación temporal de la construc- ción de edificios por barrios}

El siguiente grupo de figuras (16 a 18), permite observar la variación en el tiempo y el espacio, de la construcción de edificios en Medellín. Como es lógico, dicho comportamiento es creciente tal como lo muestra la figura 15 para toda el área de estudio.

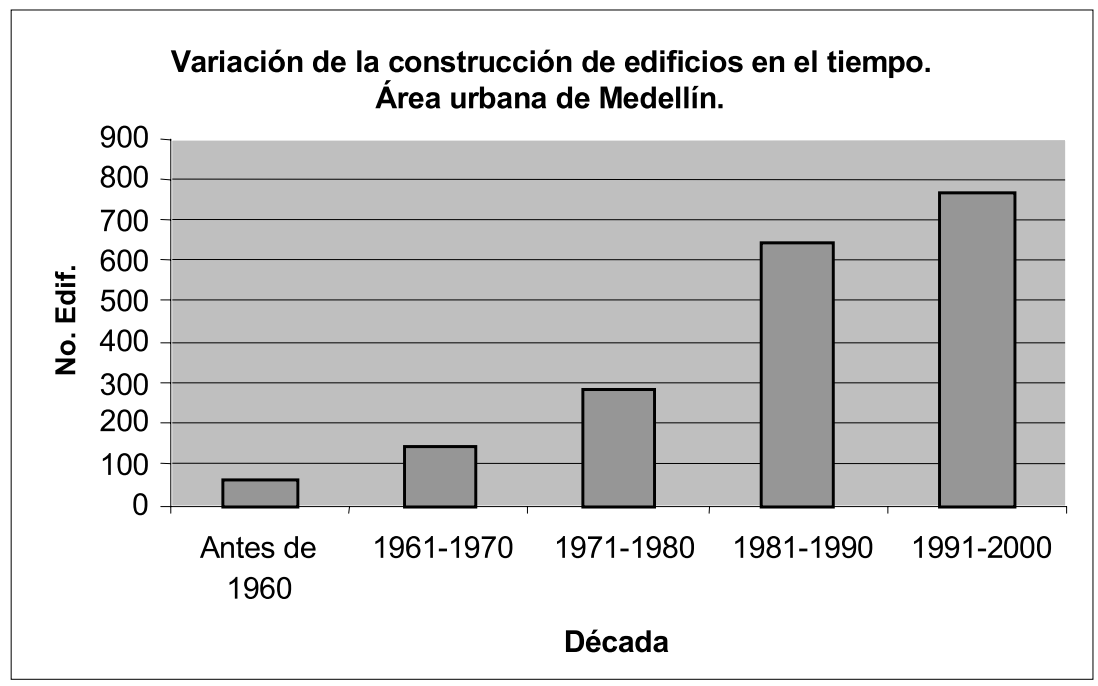

Fuente: Trabajo de campo.

\section{Figura 15.}

98 Fabio de Jesús Vélez Macías 

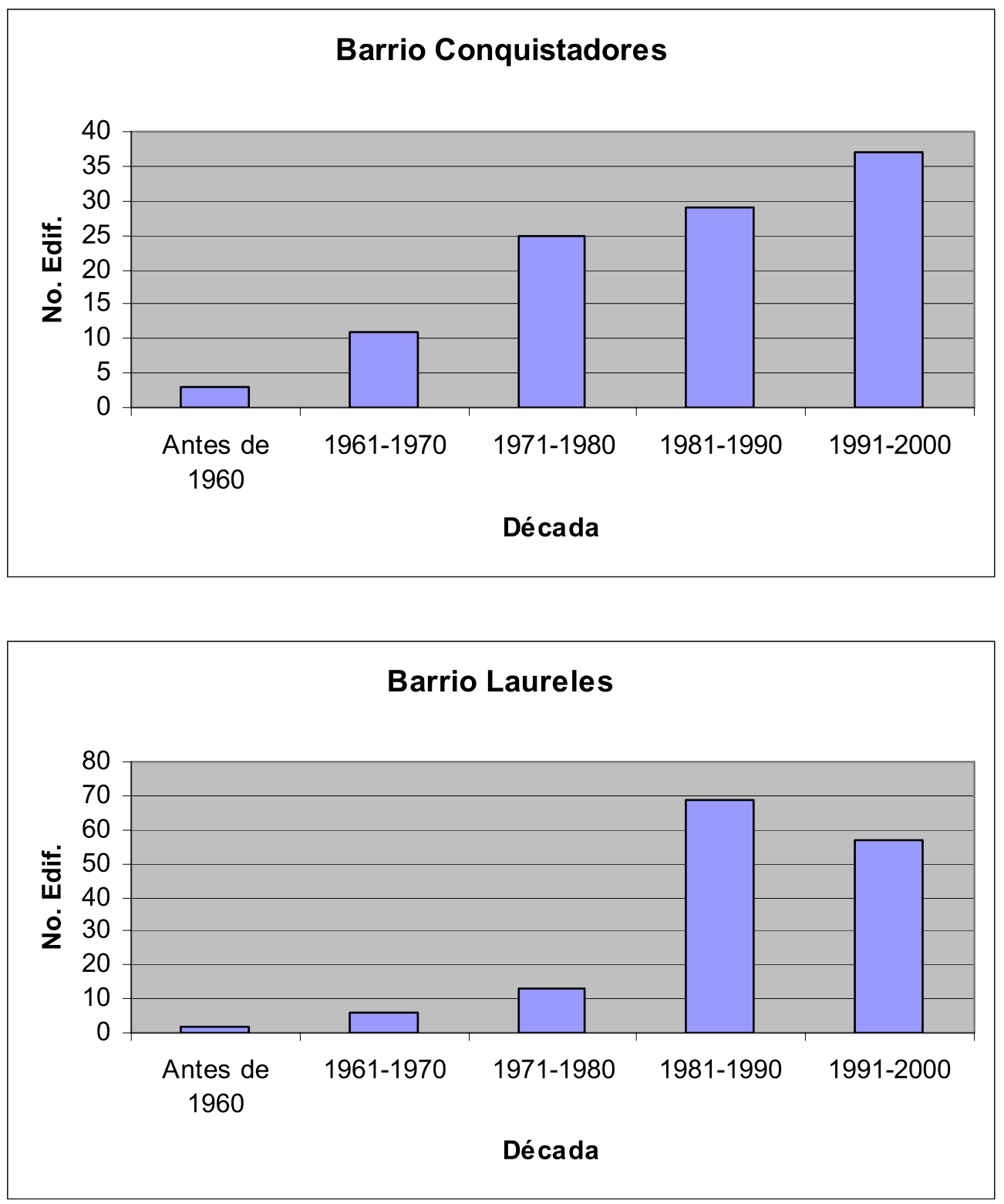

Fuente: Trabajo de campo.

Figura 16. 

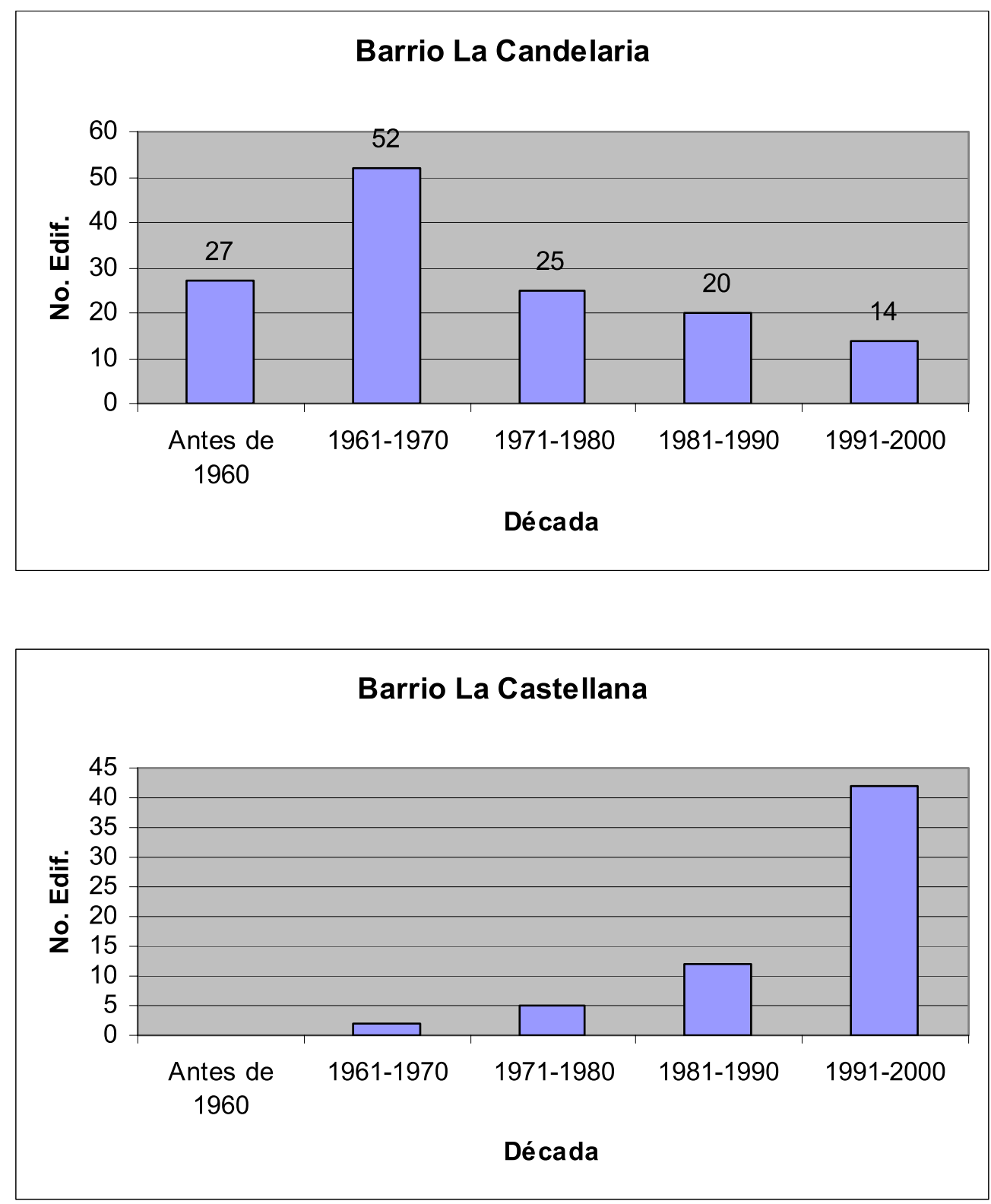

Fuente: Trabajo de campo.

\section{Figura 17.}

100 Fabio de Jesús Vélez Macías 

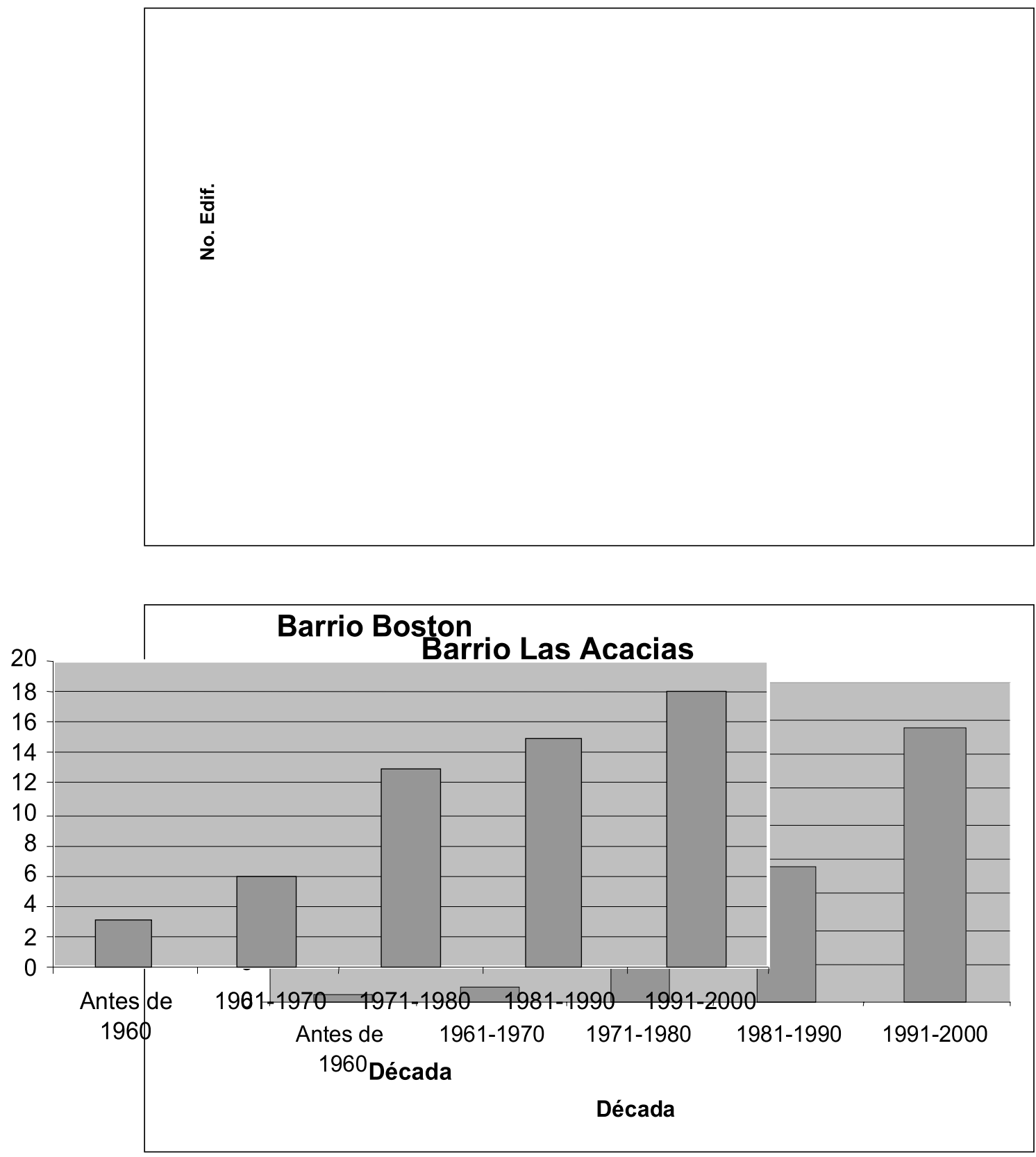

Fuente: Trabajo de campo.

Figura 18. 
Observando los casos particulares de aquellos barrios que contienen el mayor número de edificios, se puede detectar que La Candelaria se sale del patrón de comportamiento ya que como se mencionó anteriormente, es uno de los barrios más antiguos de Medellín además de que contiene el CBD, y tuvo su auge de la construcción en la década de 1970. También es observable que la caída de la tasa de crecimiento en este barrio, además de los factores económicos de efecto general, se puede deber a aspectos tales como la degradación del sector por las ventas callejeras, la inseguridad, la congestión del tráfico, los altos niveles de contaminación y la saturación de edificios de la zona. Esto ha preocupado a la administración municipal por lo que ha establecido políticas para incentivar el regreso de moradores a la zona y recuperar un espacio que es considerado tierra de nadie.

Los barrios seleccionados para ilustrar el crecimiento de los edificios por décadas en las figuras 16 a 18 , muestran un comportamiento similar, exceptuando como ya se explicó, el barrio La Candelaria. Particularmente en Laureles es apreciable el disparo de la construcción en la década del 90 que lo ha llevado a los primer lugares de los barrios con mayor número de edificios de la ciudad.

Con estas consideraciones, se elaboró la matriz que se presentó en la tabla 1 para cada una de las cuatro décadas tenidas en cuenta para el estudio. Utilizando el programa SAS para la regresión lineal por el método de stepwise, se hizo el análisis estadístico corriendo el programa para varias alternativas que permitía el conjunto de datos: ordenados por décadas, por barrio, por número de edificios ya que los niveles de significancia estuvieron por fuera de lo asumido. Finalmente se llegó a los resultados:

\section{Década de 1990:}

Ninguna variable logró un nivel de significancia del 0.15 . Todos los coeficientes parciales de regresión son iguales a 0 .

Concluída la descripción del fenómeno de crecimiento vertical y los más importantes aspectos que se destacaron a partir de la información recolectada, que dan respuesta a la dinámica del fenómeno. Se presenta a continuación el análisis de resultados del modelo estadístico que da cuenta del análisis de los factores.

A partir de la ejecución del SAS (tabla 6), para las décadas del 70 y el 80 la hipótesis es aceptada: es decir, por lo menos una de las variables propuestas explica en parte el que haya edificios en un barrio de Medellín. Para la década del 70 , la regresión lineal muestra que $\mathrm{R}^{2}$ (coeficiente de determinación) es de 0.54 , es decir, la variación de $y$ (número de edificios de un barrio) está explicado en un $54 \%$ por el modelo estadístico propuesto: $y=-42.314+0.00008868 X_{1}$ $+10.230 X_{2}$.

Ello significa que el precio del suelo y la restricción de construcción en altura explican parcialmente el crecimiento ver- 
Tabla 6

Resultados Estadísticos

\begin{tabular}{|c|c|c|c|c|}
\hline \multicolumn{5}{|c|}{ Década de 1970: } \\
\hline Paso & Variable & $\mathrm{R} 2$ parcial & $\mathrm{R} 2$ modelo & Prob $>F$ \\
\hline 1 & $\mathbf{X 1}$ & 0.3347 & 0.347 & 0.0488 \\
\hline 2 & $\mathbf{X} 2$ & 0.2092 & 0.544 & 0.727 \\
\hline \multicolumn{2}{|l|}{ Variable } & \multicolumn{2}{|c|}{ Parámetro estimado } & Prob $>F$ \\
\hline \multicolumn{2}{|l|}{ Intercepto } & \multicolumn{2}{|l|}{-42.314} & 0.0371 \\
\hline \multicolumn{2}{|l|}{$\mathbf{X 1}$} & \multicolumn{2}{|l|}{0.00008868} & 0.0098 \\
\hline \multicolumn{2}{|l|}{$\mathbf{X} 2$} & \multicolumn{2}{|l|}{10.230} & 0.727 \\
\hline \multicolumn{5}{|c|}{ Década de 1980: } \\
\hline Paso & Variable & $\mathrm{R} 2$ parcial & R2 modelo & Prob $>F$ \\
\hline 1 & $\mathbf{X 5}$ & 0.8442 & 0.8442 & 0.0002 \\
\hline \multicolumn{2}{|l|}{ Variable } & \multicolumn{2}{|c|}{ Parámetro estimado } & Prob $>F$ \\
\hline \multicolumn{2}{|l|}{ Intercepto } & \multicolumn{2}{|c|}{127.1} & 0.001 \\
\hline \multicolumn{2}{|l|}{ X5 } & \multicolumn{2}{|l|}{-58.1} & 0.0002 \\
\hline
\end{tabular}

Fuente: Análisis con el SAS.

tical en esa década. Esta ecuación es solo válida para valores de $y$ (número de edificios) entre 1 y 25 , precio del suelo entre 238.292 y 492.278 pesos $/ \mathrm{m}^{2}$ y que no haya restricción de altura.

Para la década del 80, la regresión lineal muestra que $\mathrm{R}^{2}$ (coeficiente de determinación) es de 0.844 , es decir, la variación de $y$ (número de edificios de un barrio) está explicada en un $84.4 \%$ por el modelo estadístico propuesto: $y=127.1$ $-58.1 X_{5}$

Esta vez, es el uso previo del predio el que explica en $84.4 \%$ a la variable dependiente $y$.
El número de datos utilizados fue muy escaso con respecto a la base inicial, debido a las restricciones que se presentaron en complementar la información y que indujeron a que se constituyera una matriz muy pequeña en donde el aspecto aleatorio de los datos no se pudo controlar.

Como todo modelo matemático que intenta explicar un fenómeno tan complejo como la decisión de construir edificios en un barrio, debe ser manejado con todas las reservas posibles ya que los factores involucrados están relacionados entre otras, con las acciones humanas y eso ya implica niveles de 
acercamiento a la realidad muy precarios. El acopio de un conjunto de datos apropiado es muy importante, porque como pudo observarse, no funciona en todos los casos en que se quiere implementar un modelo estadístico.

La variable más directamente relacionada con el fenómeno de crecimiento vertical es el precio del suelo. Es una afirmación obvia pero cuya tajante confirmación en el modelo no fue tan contundente. En este caso, cabe adjudicarle la culpa al modelo por las limitantes que se encontraron en extender a toda el área de estudio la aplicación de las variables en consideración. Las otras variables, restricción de la construcción en altura en el primer modelo y el uso previo del predio en el segundo modelo requerirán de más información en el tiempo para corroborar su influencia.

Para el resto de variables, también se deberá proseguir con la recopilación de datos que hagan más amplia la posibilidad de probar su peso en la explicación del fenómeno.

Aunque el comportamiento de la construcción está sujeto a variaciones cíclicas de auge y recesión propiciadas por las condiciones del mercado y los cambios económicos nacionales, el hecho de que la construcción de edificios se explique en el modelo estadístico para la década del 70 , por las variables precio del suelo y restricción de la construcción en altura se debe a la inyección de capital que tuvo el sector de la construcción, proveniente de la economía del narcotráfico y por supuesto, de las políticas nacionales para coadyuvar el problema de la vivienda. Esto generó que los precios del suelo se elevaran en forma sustacial por la especulación, y que dicha variable tuviera la importancia que refleja el modelo. La restricción de la construcción jugó un papel importante porque, previo a una reglamentación proveniente del POT, existían unas áreas de tamaño apreciable que estaban constreñidas para su desarrollo vertical y que hoy día se han reducido y puestas a consideración de otros criterios bajo la reglamentación del Plan de Ordenamiento.

En la década del 80 ya la variable precio del suelo se había estabilizado e incluso en algunos casos, comenzado a bajar, como reflejo de cambios en las políticas de inversión en el sector de la construcción y la persecución a los dineros provenientes del narcotráfico. Entonces resultan como foco de atención, más que como factor de la construcción en altura, los predios rasos apetecidos por el menor costo que implica construir en ellos.

Una posible interpretación para que el costo del suelo no hubiera tenido peso en la explicación del fenómeno, durante la década del 90, es el descenso relativo en el precio del suelo que ha ocurrido en dicho período. De hecho, los precios de la propiedad han disminuido considerablemente y esto se refleja en la parálisis del sector constructivo. La especulación en el precio dejó de ser preponderante y la demanda de vivienda nueva en edificios cayó dramáticamente por la crisis del sistema UPAC. 


\section{Análisis espacial de la ubicación de los edificios}

Sobre la existencia de patrones en la localización de los edificios, se probó la metodología propuesta por Gámir para los siguientes barrios: Rosales, Fátima, Conquistadores, Laureles, Castellana, Simón
Bolívar, Florida Nueva, Velódromo, Estadio, Suramericana, Alejandría, Los Balsos N.2, que contaban con suficientes puntos correspondientes a edificios, como para utilizar el método. Para el efecto, se utilizó el programa ArcView que permitió la medición de las distancias. La tabla 7 resume la información necesaria para el proceso.

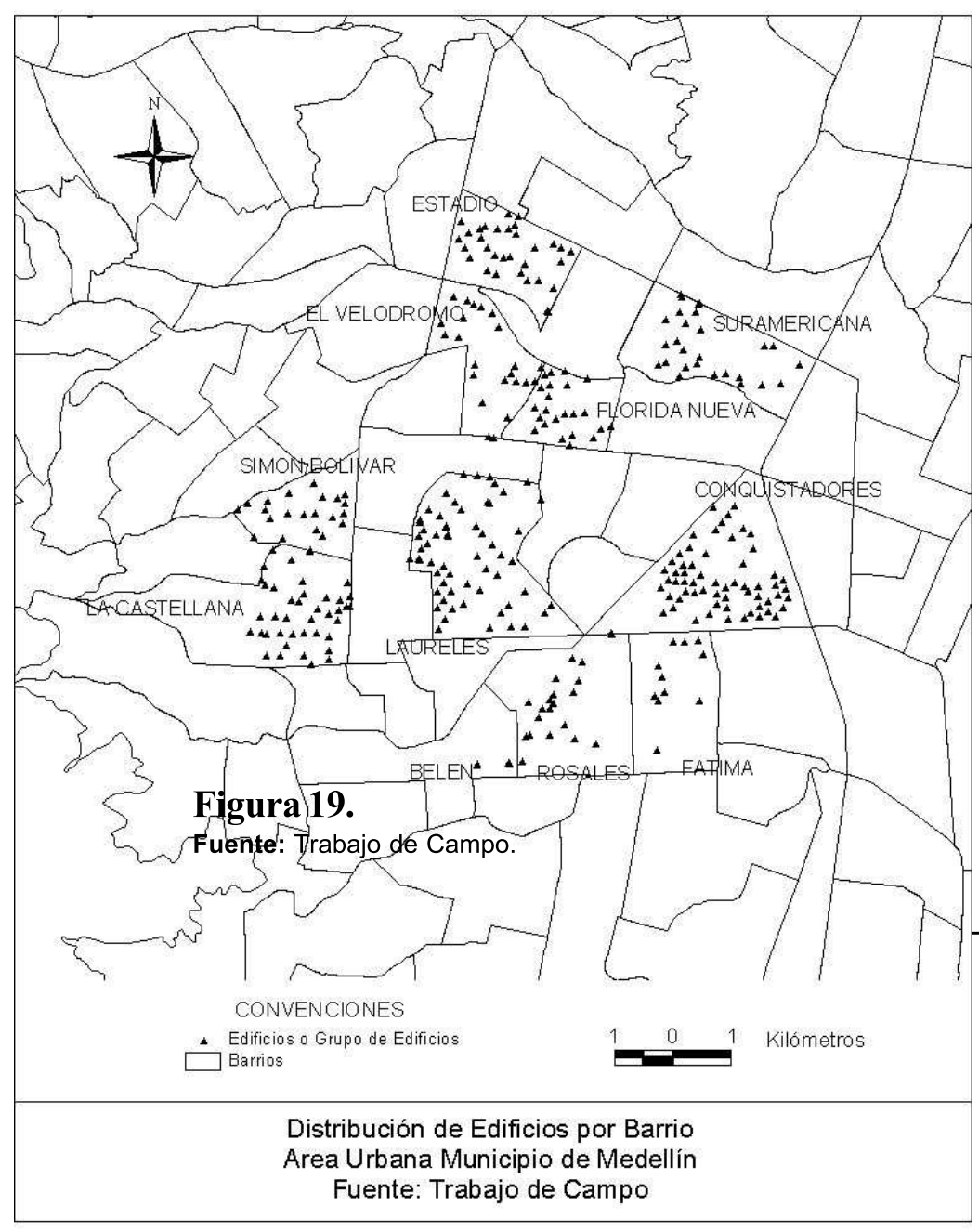

Perspectiva Geográfica 105 


\begin{tabular}{|l|c|c|c|c|c|}
\hline & $\begin{array}{c}\text { N (número } \\
\text { de datos) }\end{array}$ & $\begin{array}{c}\text { Distancia } \\
\text { promedio (m) }\end{array}$ & área (m2) & da & R(1) \\
\hline ROSALES & 62 & 178 & 605743 & 49.42 & 3.60 \\
\hline FATIMA & 40 & 273 & 435923 & 52.20 & 5.23 \\
\hline CONQUISTADORES & 271 & 165 & 687387 & 25.18 & 6.55 \\
\hline LAURELES & 271 & 166 & 702353 & 25.45 & 6.52 \\
\hline CASTELLANA & 158 & 160 & 690401 & 33.05 & 4.84 \\
\hline SIMON BOLIVAR & 83 & 120 & 292502 & 29.68 & 4.04 \\
\hline FLORIDA NUEVA & 95 & 145 & 249529 & 25.63 & 5.66 \\
\hline VELODROMO & 72 & 163 & 367056 & 35.70 & 4.57 \\
\hline ESTADIO & 97 & 142 & 366861 & 30.75 & 4.62 \\
\hline SURAMERICANA & 68 & 125 & 488988 & 42.40 & 2.95 \\
\hline ALEJANDRIA & 36 & 202 & 430278 & 54.66 & 3.70 \\
\hline LOS BALSOS N.2 & 36 & 207 & 487823 & 58.20 & 3.56 \\
\hline
\end{tabular}

Gámir (1995), propone la siguiente clasificación:
$\mathrm{R}(1)=1$,
distribución aleatoria del fenómeno
$\mathrm{R}(1)=0, \quad$ distribución concentrada del fenómeno
$\mathrm{R}(1)>1$, distribución dispersa del fenómeno

\section{Los patrones}

De acuerdo con la metodología y los valores hallados de $\mathrm{R}(1)$, la distribución del fenómeno de crecimiento vertical en los barrios seleccionados es de tipo dispersa.

Aunque el patrón determinado por el método matemático muestra una conjunto disperso de edificios, a nivel de barrio se observa a simple vista y con el soporte de la información recogida en campo, que la concentración de estos edificios se hace en uno cuantos barrios. Ya, dentro de la unidad espacial, no hay preferencia en la ubicación de los edificios.

\section{Las tendencias}

La tendencia de dicho crecimiento está por ahora en situación crítica por la recesión económica que afronta el país y repercute en las inversiones en construcción y en la adquisición de vivienda. Cuando se supere este período es de esperarse que el sector constructivo se reactive y continúe emplazando edificios en donde estos han tenido mayor demanda de consumo como son los barrios de las comunas 11, 12 y 14 .

Muy posiblemente también se vea la continuación de la colonización de ciertas colinas al occidente y oriente de la ciudad (comuna 16). La entrada en vigencia del Plan de Ordenamiento Territorial traerá supuestamente un mayor orden y control 
en la construcción, que buscará, así sea tardíamente, la armonía del uso del suelo y los intereses ciudadanos enfocados en el bienestar y últimamente, en la preservación del medio ambiente.

\section{Conclusiones y recomendaciones}

La construcción de edificios en Medellín ha estado sujeta a los fenómenos socioeconómicos del país y de la ciudad. Esto se puede observar en la similitud entre los datos correspondientes a la variación del precio del suelo y la aparición o receso de nuevos edificios en el tiempo. Particularmente este estudio ha coincidido con un período de caída en el sector de la construcción que por ahora ha dejado una vista congelada de lo que ha sido la evolución de los edificios en la ciudad.

El estudio ha mostrado con cifras, que la concentración de edificios de la ciudad se halla en tres comunas y que de ellas sobresalen tres barrios como los que más construcciones de este tipo poseen. Una cuarta comuna, al occidente de la ciudad, comienza a registrar un crecimiento acelerado y sostenido en la construcción de edificios, lo que la convierte en una importante zona para observar el desarrollo del fenómeno en los próximos años.

Es de destacar el Centro de Medellín, que ha tenido un comportamiento típico en cuanto al crecimiento vertical. Su manifestación ha evidenciado los efectos del precio del suelo, la importancia cul- tural y social de la zona, hasta el punto de verse hoy en día saturado de edificios aún en zonas que debieron tener un tratamiento más cuidadoso por sus cualidades ambientales y geotécnicas. $\mathrm{Su}$ estancamiento se ve reforzado por la degradación causada por las ventas ambulantes, la indigencia y la inseguridad, que buscan la mayor afluencia del público que aún disfruta del CBD.

La tendencia en el crecimiento vertical se da en los barrios que han mostrado esta vocación y demanda en las dos últimas décadas, particularmente los barrios Laureles y Conquistadores. Sin embargo se notan varios barrios activos con crecimiento relativamente constante en el número de edificios. Es el caso de algunos barrios de la periferia, al occidente y al oriente, que a costa de prescindir de algunos bosques que ocupaban zonas aún no integradas a la ciudad, presentan nuevas urbanizaciones de altos edificios en lo que se augura como una nueva franja del crecimiento vertical. Esta integración de nuevo suelo urbano se hace a partir de la modificación de límites en las instancias político administrativas, lo que lógicamente se ve retribuído en un beneficio económico considerable para los urbanizadores. Los impactos ambientales que esto produce son palpables e inmediatos, además de que se generan conflictos de tipo social y económico, debido a que entran nuevos pobladores con un status diferente al de los habitantes ya establecidos, a vivir en predios que son delimitados con barreras físicas y visuales y presionan los recursos y vías de acceso. La estratificación socio 
económica del barrio se fracciona y algunos pobladores antiguos se pueden ver afectados.

Si de dar soluciones a la demanda de vivienda se trata, la ciudad cuenta con un banco de tierras que algún día en el futuro será objeto de comercio y de actividades constructivas. Se trata del aeropuerto Olaya Herrera que con su cono de operaciones ha restringido por años el crecimiento de la ciudad y ha incomunicado al suroriente del suroccidente.

Lastimosamente este estudio no tuvo en cuenta una cifra importante de edificaciones que aportan los típicos edificios de cuatro pisos con semisótano. Estos son abundantes y representan una tendencia a considerar en estudios posteriores.

Los objetivos de la investigación se cumplieron ya que se aportó en la caracterización de las variables, la demostración de la hipótesis se completó aunque resultó un producto que normalmente no se pretende en los proyectos, es decir, no fue aprobada en su totalidad sino en sólo dos de los tres períodos analizados. El estudio de los patrones y tendencias se logró teniendo a la mano los datos de la evolución de la redensificación y acudiendo a la metodología propuesta por Gámir para análisis de patrones.

Con fines prácticos, este trabajo puede servir como aporte a la administración municipal para conocer en primer término un inventario de los edificios de la ciudad, $\mathrm{y}$ tomar las consideraciones y explicaciones sobre la manifestación y dinámica del fenómeno del crecimiento vertical para ser tenidas en cuenta en la toma de decisiones sobre el ordenamiento del territorio. Particularmente en aquellos barrios que están siendo intervenidos con mayor predilección por los constructores y que pueden llegar a presentar problemas como la saturación visual, de vías y servicios, demanda de recursos, cambios en las políticas de uso del suelo.

Este estudio ha suministrado una base de datos importante que podría permitir mayores análisis. Sin embargo es manifiesto el vacío de información que existe en las entidades encargadas de la planeación urbana que ha impedido una recopilación más acorde con el esfuerzo que requirió levantar en el campo todos los edificios de Medellín. Por lo tanto es recomendable que la labor de manejo de información sea más acuciosa y asumida con la importancia que tiene por parte de las entidades encargadas. Preocupa la labor que hacen las curadurías ya que están retrasando o dejando de hacer una función que va en desmedro de las herramientas que permiten los análisis y la toma de decisiones.

De igual modo, se debe tratar de adquirir información que se sale de los estándares habituales y que posiblemente por los costos que implica, sea esquivada por las entidades que más directamente las involucra. Particularmente tiene importancia el monitoreo de variables de tipo ambiental en diferentes zonas que 
están altamente pobladas por edificios. Este tipo de monitoreos no pasan por ahora, de ser pequeños intentos puntuales de medición de un puñado de parámetros que luego se ven ahogados en el vacío de la información.

El POT para Medellín ha contemplado medidas tendientes al control del crecimiento vertical de ciertas zonas y la fijación de valores para parámetros como el Índice de Construcción y el Índice de Ocupación que pretenden controlar la construcción indiscriminada de edificios. En caso de que se contase con las herramientas de tipo legal y político, sería posible impedir que en el futuro se sobrepasen dichos coeficientes y se construyan obras que van en detrimento de los habitantes que las moran y de su seguridad misma.

Este mismo Plan procura terminar con la cultura gestionadora que ha reinado en la ciudad y que ha permitido que la mayor parte de las obras de desarrollo sean entendidas por los administradores como una oportunidad para echar a tierra unos cuantos edificios que a pesar de su valor histórico o cultural, representan grandes erogaciones por mantenimiento, $\mathrm{y}$ de otro lado, la carrera desenfrenada por pavimentar cuanto pedazo de suelo quede por ahí descubierto, porque es entendido como una oportunidad para ser invadido por la indigencia o aprovechado para otros fines poco salubres.

Se recomienda que este tipo de estudios sea replicado en otras ciudades de tal forma que se permita un análisis espacial de orden mayor, y se ayude a profundizar en un tema tan poco explorado en nuestro medio.

Es indudable que las circunstancias actuales llevarán a que en un futuro no muy lejano la población que habita las ciudades representarán casi la totalidad del porcentaje de la población. Esto hará que los problemas urbanos sean mayores y por tanto la preparación en recursos informáticos y humanos serán vitales para afrontar estos grandes retos que se avecinan. En este contexto la Geografía Urbana tiene un papel muy importante que jugar tanto en el desarrollo de metodologías, nuevas teorías, como en el entendimiento de la información que se obtenga. Se espera que esta haya sido una contribución que vaya en esa dirección. 


\section{Bibliografaía}

AREAMETROPOLITANADEL VALLE DE ABURRÁ. Estatuto Metropolitano de Planeación. Usos del suelo, urbanismo y construcción. Medellín: 1988.

Bravo Betancur, José María. Geografía Urbana. (Spi).

Bourne, Larry S. Internal structure of the city. New York: Oxford, 1971.

Carter, Harold. El estudio de la geografía urbana. Madrid: Instituto de Administración Local, 1983.

Estrada Cano, Marcela. Medellín bioclimático: su edificio de oficinas a través del siglo. En: BANCO DE LA REPÚBLICA. Boletín cultural y bibliográfico. Bogotá: Biblioteca Luis Angel Arango, 1995. Vol. 30, $\mathrm{N}^{\circ} 33$. pp. 74-92.

Gámir Orueta, Agustín, Ruiz Pérez, Mauricio y Seguí Pons, Joana María. Prácticas de análisis espacial. Barcelona: Oikos-tau, 1995.

Hoch, Irving. La ciudad tridimensional: el espacio urbano cerrado. (Spi). pp. 83 - 147.

Jaramillo, Samuel. Hacia una teoría de la renta del suelo urbano. Bogotá: Uniandes, 1994.

Knox, Paul L. Urbanization: an introduction to urban geography. New Jersey: Prentice Hall, 1994.

LA LONJA DE PROPIEDAD RAÍZ DE MEDELLÍN Y ANTIOQUIA. Estudio del valor del suelo en Medellín y el Área Metropolitana. Medellín: La Lonja de Propiedad Raíz, 1999.

MUNICIPIO DE MEDELLÍN. DEPARTAMENTO ADMINISTRATIVO DE PLANEACIÓN. Revista Planeación Metropolitana $N^{\circ} 1$. Separata 1 . Avances de Investigación. Medellín: eneromarzo de 1991.

Estudio del Centro de la ciudad, 1968. Medellín: 1969.

Perloff, Harvey S. La calidad del medio ambiente urbano. Barcelona: Oikos-tau, 1973.

REVISTAINGENIERÍA, ARQUITECTURA, CONSTRUCCIÓN. La carrera de los rascacielos. Vol. $12 \mathrm{~N}^{\circ} 6$ (junio de 1971).

Zárate Martín, Antonio. El mosaico urbano: organización interna y vida en las ciudades. Colombia: Cincel - Kapelusz, 1992.

El espacio interior de la ciudad. Espacios sociedades. Madrid: Síntesis, 1991.

110 Fabio de Jesús Vélez Macías 